\begin{tabular}{|l|l|l|l|l|l|}
\hline MUNIBE Antropologia-Arkeologia & $n^{\circ} 65$ & $249-268$ & DONOSTIA & 2014 & ISSN 1132-2217 • eISSN 2172-4555 \\
\hline
\end{tabular}

\title{
Ser minero. El contexto cultural generado por la minería industrial (siglos XIX-XX) en el sur de la Península Ibérica
}

\author{
Miners. The cultural context generated by the mining industry \\ $\left(19^{\text {th }}-20^{\text {th }}\right.$ centuries) in the southern Iberian Peninsula
}

KEY WORDS: intangible heritage, mining history, economic colonialism, industrial paternalism, globalization.

PALABRAS CLAVES: patrimonio inmaterial, historia de la minería, colonialismo económico, paternalismo industrial, globalización.

GAKO-HITZAK: ondare ez-materiala, meatzaritzaren historia, kolonialismo ekonomikoa, paternalismo industriala, globalizazioa.

Juan Manuel CANO SANCHIZ(1)

\begin{abstract}
The cultural context generated by the mining industry works as an unifying force in mining enclaves, as well as an element distinguishing them from surrounding territories. Mining culture, formed as the common answer to the circumstances produced by the mine, is thereby a hallmark of mining communities. Several agents participated in the formation of this identity system, such as the working conditions, the relationship with death, the sense of class, progress, economic colonialism or the labour movement. This paper aims to track the role played by these and other elements in the construction of a specific social group: the contemporary mining people in the South of the Iberian Peninsula, as the result of hybridism between globalization and endemism. In doing so, we combine archaeological and anthropological methods through a wide range of sources of information: material culture, oral memory, written/visual historical documents and tourist guides and brochures.

This paper seeks to shed new light on the conceptualisation and characterisation of mining villages as a contemporary social unit in the industrialised world. It studies a sample of mining enclaves in the south of the Iberian Peninsula (without neglecting the international context), including villages located in the Iberian Pyrite Belt (Huelva, Seville and southern Portugal), Sierra Morena (Seville, Cordoba, Jaen), Sierra Almagrera (Almeria) and the Cartagena-La Unión Mining District (Murcia). The study follows a clearly cultural approach, over and above such aspects as the economy or technology, which are usual in traditional historiographies of mining. In short, it attempts a descriptive approach to the cultural context created by industrial mining through its physical and intangible manifestations: architecture, migration, colonialism, ideology, religion, tradition, gastronomy, fashion, folklore, daily life, sport and leisure. To achieve this, from the methodological point of view, the text is characterised by its transversal nature and the complementary application of typical tools of such disciplines as Industrial Archaeology, Cultural Anthropology and Ethnography.

Through this study, it can be concluded that mining culture functions as a differentiating element, while the mine is defined as a territorial item with powerful spatial demarcation in scenic, economic and social terms. One of the most interesting characteristics of the mine as a habitat is, therefore, its ability to generate a different (and distinctive) social collective through the combination of pre-existing cultural traits. Industrial mining enclaves are thus a place for meeting and confrontation, where the native population lives together with immigrants, the autochthonous material culture coexists with that from outside, and local traditions alternate with foreign customs.

The ultimate goal of this study is to identify mining culture as a factor (or product) of globalisation, although it does not aspire to go beyond opening a topic of discussion. Indeed, the creation of international networks by capital, the characteristic mobility of mine workers (labourers, office workers and engineers) and the transfer of technology facilitated the homogenization of economic and technical systems which was also reflected in the social realm: the production of a specific cultural context (without forgetting the particularities of each region) in relation with mining villages. In the southern Iberian Peninsula this has even survived the end of mining activity and can still be detected as a hallmark of those communities.
\end{abstract}

\section{RESUMEN}

El contexto cultural generado por la minería industrial aparece como un elemento aglutinante entre enclaves mineros, al tiempo que diferenciador respecto al territorio en el que se insertan. La cultura minera, configurada como respuesta común ante las circunstancias que determina la mina, funciona así como seña de identidad para estas poblaciones. En la conformación de este sistema identitario participaron diversos agentes, como las condiciones de trabajo, la relación con la muerte, el sentido de clase, el progreso, el colonialismo y el movimiento obrero. El presente trabajo pretende rastrear el papel jugado por dichos elementos en la construcción de un colectivo social concreto, producto de la hibridación entre globalización y endemismo: el pueblo minero contemporáneo del sur de la Península Ibérica. Para ello, se combinan técnicas de estudio arqueológicas y antropológicas (de campo y de escritorio), que se aplican sobre un amplio abanico de fuentes: cultura material, memoria oral, documentación histórica e informaciones turísticas.

(1) Grupo de Investigación Sísifo (PAIDI HUM-236), Universidad de Córdoba. 


\section{LABURPENA}

Meatzaritza industrialak sortutako testuinguru kulturala meatzaritzako guneen arteko elementu lotzailea da eta meatzaritza txertatzen den lurraldeei dagokienez, bereizgarriak ere badira. Meatzaritzaren kultura meatzearen ezaugarriei erantzuteko sortzen da eta toki horien nortasun-adierazgarri gisa funtzionatzen du. Nortasun-sistema hori eratzeko, hainbat eragilek hartzen dute parte; besteak beste, hauek: lan-baldintzak, heriotzarekiko harremana, klasearen zentzua, aurrerabidea, kolonialismoa eta langile-mugimendua. Lan honen helburua elementu horiek gizarte-talde jakin bat eraikitzeko zer zeregin izan duten aztertzea da, globalizazioaren eta endemismoaren arteko hibridazioaren emaitza gisa: Iberiar penintsularen hegoaldeko herri meatzari garaikidea. Horretarako, arkeologiako eta antropologiako ikerketa-teknikak (bertatik bertarako lana eta idazmahaikoa) uztartzen dira askotariko iturrietan aplikatuta: kultura materiala, ahozko memoria, dokumentazio historikoa eta informazio turistikoak.

\section{1.- CONTEXTO FÍSICO: EL CAMPAMENTO MINERO}

La cultura de la mina tiene un espacio propio: el campamento minero, indisociable de las áreas de extracción. Se trata, en términos generales, de un asentamiento tipo, que experimentó una rápida expansión y homogeneización por todo el planeta con la industrialización de los países más desarrollados y la aparición de las nuevas tecnologías y demandas características del mundo contemporáneo (vid. CANO, 2012b). Su dispersión, por tanto, es global, como ponen de manifiesto Basset Mines en Inglaterra (PALMER y NEAVERSON, 1987), São Domingos en Portugal (ALVES, 1997), Sewell en Chile (GARCÍA, 2005), el Copper Country norteame-
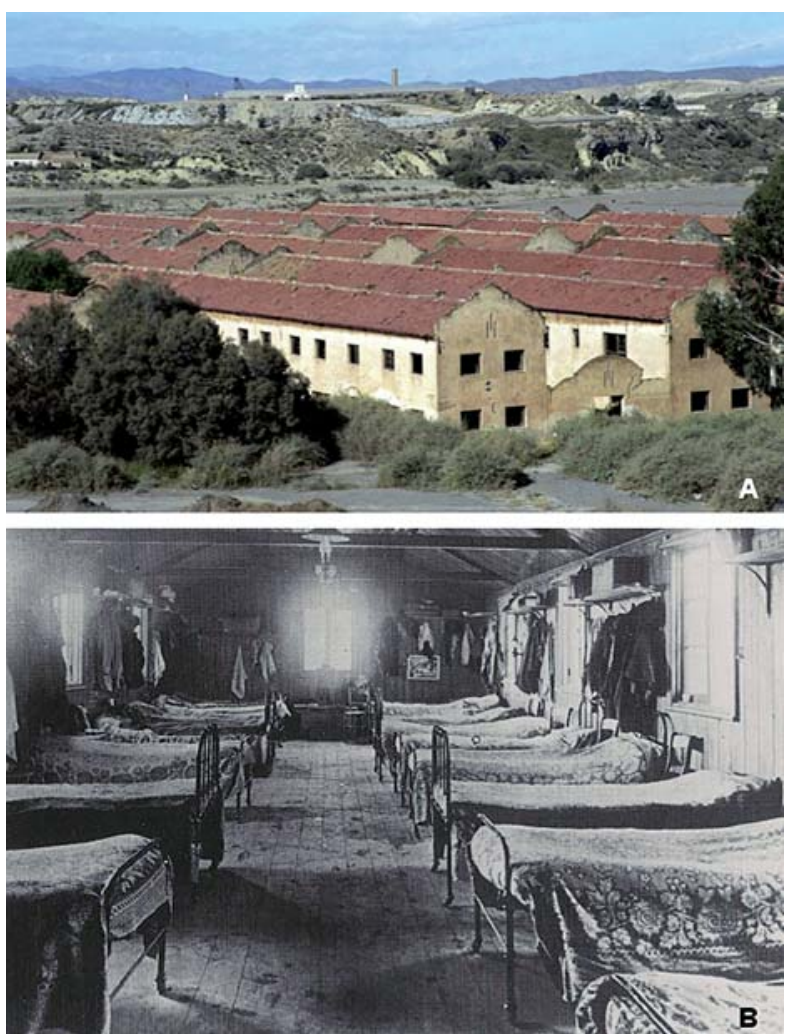

Fig. 1. A: Cuarteles para los mineros de El Arteal, frente a las minas de Herrerías, en la Sierra Almagrera (Almería) (GONZÁLEZ y SANCHIS, 2012: 33. Fig. 31). B: Interior de una barraca de mineros en Frongoch Mine (Gales) a principios del s. XX (WILLIES, 2009: 30) / A: Barracks for the miners of El Arteal, nearby the Herrerías mine, Sierra Almagrera (Almería, Spain) (GONZÁLEZ y SANCHIS, 2012: 33, Fig. 31). B: Miners' barrack at Frongoch Mine (Wales), c. 1900 (WILLIES, 2009: 30). ricano (FOSTER, 1988), Broken Hill en Australia (KEARNS, 1982), Millwood en Sudáfrica (OLIVIER y OLIVIER, 2005) o Hashima Island en Japón (BURKE-GAFFNEY, 2002), entre tantos otros ejemplos.

Tras la creación de todos estos poblados se situaron a menudo las mismas causas, como el aislamiento del lugar de trabajo respecto a los asentamientos preexistentes, la necesidad de disponer de plantilla fija, o la participación del grueso de sus habitantes en la actividad minera (vid. ARENAS, 2007: 224). Es por ello que frecuentemente se dotaron de la misma infraestructura y crecieron de forma parecida (aun teniendo en cuenta las particularidades aportadas por cada región), lo que terminó generando un nuevo tipo de paisaje urbano modelado por la confrontación entre globalización y tradición local.

Todo lo dicho es rastreable en el sur de la Península Ibérica. Allí los campamentos mineros también se levantaron ex profeso para acoger cerca de la mina a la masa humana que había encontrado en ella su puesto de trabajo, sobre todo durante el boom minero de finales del siglo XIX - principios del XX, que se caracteriza por la llegada masiva de capitales extranjeros y la internacionalización de la actividad minera (CHASTAGNARET, 2000).

\subsection{Vivienda}

En este sistema globalizado el minero se define como un trabajador de fuerte movilidad, lo que en buena medida marca el tipo de vivienda propio del campamento. Así, el cuartel minero o barracón, normalmente constituido por una única nave de planta rectangular cubierta a dos aguas, fue una de las unidades más populares. En ocasiones el interior se compartimentó en pequeñas habitaciones o modestos hogares, según que casos, mientras que otras veces se siguió el modelo de cuartel militar, en el que todos los mineros compartían el mismo espacio -ejemplos en Frongoch Mine, Gales (vid. WILLIES, 2009: 30)- (Fig. 1).

Aun cuando existen ejemplos de gratuidad ( $v i d$. SIERRA, 1985: 70), lo habitual fue que los operarios tuvieran que alquilar estas viviendas de las compañías explotadoras. Así sucedía en la década de 1910 en Cerro Muriano -Córdoba- (CAVANILLAS, 1915: 43; PENCO, 2010), Puertollano -Ciudad Real- (FERNÁNDEZ CALVO, 
1987: 198) o Villanueva del Río y Minas ${ }^{1}$-Sevilla- (SIERRA, 1987: 673), entre otros lugares. El capital, propietario en muchas ocasiones de la mayor parte del parque inmobiliario, ejercía de ese modo un control más efectivo sobre la mano de obra, como bien ejemplifica Riotinto -Huelva- (AVERY, 1985: 187).

Junto a los cuarteles proliferaron las chabolas, las chozas y las cuevas. En Villanueva del Río y Minas dependían de terceros y eran alquiladas por los temporeros; es decir, aquéllos que necesitaban cobijo para el breve periodo que trabajaban en la mina (SIERRA, 1987: 673). Estas precarias construcciones respondieron a un tipo muy frecuente, caracterizado por su pequeño tamaño y por el uso de materiales deleznables, como puede rastrearse en torno a las minas de Tinoca (Portugal), Riotinto, Cerro Muriano (PENCO, 2010), Peñarroya -Córdoba- o Puertollano. En esta última localidad, y en el contexto de la Primera Guerra Mundial, los recién llegados encontraban muy difícil acceder a una vivienda (o a los medios para construirla), lo que propició la aparición de numerosos barrios chabolistas, e incluso que algunos obreros recurrieran al abrigo nocturno de las escombreras, ignorando sus riesgos y toxicidad (FERNÁNDEZ CALVO, 1987: 201).

En parte como consecuencia de estas circunstancias (llegada masiva de inmigrantes, crecimiento descontrolado de los asentamientos, temporalidad, etc.), a lo largo el siglo XIX los poblados mineros suribéricos se convirtieron, con frecuencia, en espacios desordenados, tendentes al hacinamiento, ruidosos y taberneros. Como sucediera en Inglaterra durante la Revolución Industrial (ENGELS, 1976), proliferaron los suburbios marginales, en los que la vida íntima sólo podía desarrollarse en un ambiente de pobre calidad y carente de unas mínimas condiciones de habitabilidad, lo que generó entre los mineros cierto sentimiento de exclusión. Así ocurrió, por ejemplo, en Linares (Jaén) -donde en un cuarto mal ventilado podían dormir hasta doce hombres- (PEINADO y ANTA, 2010: 418; COLECTIVO PROYECTO ARRAYANES, 2007: 70; 2011: 257 y 322), las minas del sureste español (vid. MARTíNEZ CARRIÓN, 2005: 34) o el Riotinto de los primeros años de explotación británica. Avanzado el siglo XX, la situación empezó a mostrar síntomas de mejoría. Entonces se comenzó a prestar mayor cuidado a las condiciones higiénicas de los campamentos y de los lugares de trabajo, lo que incidió positivamente en la salud de los mineros (MARTíNEZ CARRIÓN, 2007: 254-255)

En cualquier caso, la tendencia general -al menos, desde el capital- fue buscar una ordenación urbana controlada y racional, así como las mejores condiciones de salubridad. Lo dicho puede comprobarse en La Carolina (Jaén), planificada a finales del siglo XIX como centro neu- rálgico de las nuevas poblaciones surgidas en torno a la actividad minera en la Sierra Morena jienense. La ciudad, que acogió a otras industrias e importantes bancos, fue equipada con una completa infraestructura de servicios y comunicación con el exterior (fundamentalmente ferroviaria). Todo lo cual dotó a su población de un dinamismo carente en otras zonas del territorio, que le permitió alcanzar altas cotas de desarrollo económico y socio-cultural (COLECTIVO PROYECTO ARRAYANES, 2007: 70).

\subsection{Arquitectura y paternalismo industrial}

El trabajo del minero se ha asociado tradicionalmente a una serie de problemas: inseguridad, alta mortandad, insalubridad, conflictividad laboral, etc. Sin embargo, junto con los inconvenientes derivados de su actividad, los mineros disfrutaron normalmente de algunas ventajas: sueldos altos para la época (especialmente comparados con los del campo), estabilidad económica; régimen de pensiones, retiro, viudedad y orfandad; abastecimiento de agua y energía eléctrica (por parte de las compañías mineras); tiempo libre, etc. Sin olvidar el acceso a unas infraestructuras rara vez presentes en las poblaciones rurales de la Sierra Morena decimonónica: hospitales, escuelas, cantinas/economatos, casinos y otros locales de ocio (CHASTAGNARET, 2000).

Estos servicios e instalaciones fueron, en numerosos casos, promocionados y gestionados desde el capital como medida para fomentar la creación de plantillas fijas, a las que reservaron buena parte de estos privilegios (SIERRA, 1990). Todo ello en un esquema internacional de marcado acento paternalista, en el que las grandes firmas buscaron disponer de una mano de obra sana, instruida, fuerte y renovada (reproducción de los mineros), pero también controlada (TONE, 1997). Otras veces, en cambio, fueron los obreros quienes crearon sus propios sistemas de cooperación y asistencia. Es el caso de las sociedades de socorros mutuos para auxiliar a enfermos y accidentados -con un interesante ejemplo en La Zarza, Huelva- o de las cooperativas de consumo (SÁNCHEZ SÁNCHEZ, 2001).

En ocasiones, la cantina funcionó más como un mecanismo de explotación que como un centro filantrópico. Los mineros de El Rincón (Hornachuelos, Córdoba), como tantos otros, recibían a principios del siglo XX sus anticipos en unos vales ${ }^{2}$ que sólo eran canjeables en la poco adecuada cantina de las minas, por lo que no podían gastar libremente su dinero (ANIEVAS, 1910: 2). La otra cara de la moneda la encontramos en Villanueva del Río y Minas, donde las necesidades de alimentación y vestido eran cubiertas por el economato (para la plantilla fija y sus fami-

'En las casas construidas por la compañía ferroviaria MZA en esta localidad sólo podían residir los trabajadores fijos en plantilla, que en 1910 pagaban por ellas entre 3 y 5 ptas. mensuales (SIERRA, 1987: 673).

2Éste fue un sistema común en todo el mundo minero, rastreable también, p. ej., en las tiendas de empresa de la minería del carbón norteamericana (CALVO, 2013). En España, y por orden del Gobierno español, los cupones-dinero desaparecieron a partir de 1915 y los pagos pasaron a efectuarse en metálico (AVERY, 1985: 238) 
lias) y la fonda económica (para los temporeros solteros). En 1910 estas instalaciones incluían matadero, carnicería y panadería (Fig. 2), mientras que lo gastado se descontaba, a precio de costo, de los jornales (SIERRA, 1987: 672). Otro caso positivo es el constituido por el economato construido con capital inglés en el Cerro del Hierro (San Nicolás del Puerto, Sevilla) 3 .

La presencia de hospitales fue asimismo usual en un ambiente de mayor preocupación por la higiene del minero (vid. CHASTAGNARET, 2000: 852-854; MARTÍNEZ CARRIÓN, 2007: 254-255), aunque no una constante. Algunos alcanzaron dimensiones considerables y estuvieron equipados con todo lo necesario, como el de Riotinto o el administrado por la Société Minière et Métallurgique de Peñarroya (SMMP) en dicha localidad (vid. PRADOS, 2011: 624). Este último no se limitaba a atender accidentados, sino que contaba también con un buen programa de medicina preventiva; destaca, en este sentido, el éxito de su campaña para erradicar el paludismo en la comarca (AUTE, 2004: 286). En otros casos, como Cerro Muriano, estas instalaciones fueron diseñadas para atender a una población más reducida, por lo que se limitaron a una pequeña enfermería dotada de botica (CANO, 2012b: 331 y 333). Normalmente era el obrero quien sufragaba estos sanatorios -otros ejemplos en Tharsis (Alosno, Huelva) o Minas Concepción (Huelva)4 - con una parte porcentual de su sueldo, si bien en ciertas compañías el servicio fue gratuito. En efecto, la Ley de acci- dentes de trabajo de 1900 estableció que los heridos en el desarrollo de su oficio debían ser atendidos sin coste alguno (SIERRA, 1987: 672), pero no obligaba a dar cobertura a los enfermos o a sus familiares.

Por otro lado, y estrechamente asociadas a los hospitales mineros, las estaciones de salvamento también jugaron un papel fundamental en lucha contra la alta mortandad de este colectivo ${ }^{5}$. Algo que puede ponerse en relación con los esfuerzos de los ingenieros córnicos para mejorar la seguridad y condiciones de trabajo de los mineros ingleses (HUDSON, 1976), o con los avances en materia de seguridad minera alcanzados en Alemania durante los siglos XIX y XX (SLOTTA, 2005).

Un ejemplo paradigmático de la preocupación por la salud de la plantilla lo encontramos en la Villanueva del Río y Minas de principios del Novecientos. Allí, la MZA construyó para sus trabajadores un hospital, una farmacia y un lazareto, al tiempo que formó un equipo compuesto por un médico, un farmacéutico, dos practicantes, dos mancebos y dos mujeres, que hacían las veces de enfermeras y limpiadoras. Aun cuando en un principio el mantenimiento de estas instalaciones corría a cuenta de los trabajadores, desde comienzos de la citada centuria el servicio pasó a ser gratuito para los mineros y sus familias, cubriendo tanto los accidentes laborales como cualquier otra enfermedad contraída (SIERRA, 1987: 672). También merece mención especial el caso de Almadén (Ciudad Real), donde la asistencia médica (con una amplia tradición que hunde sus

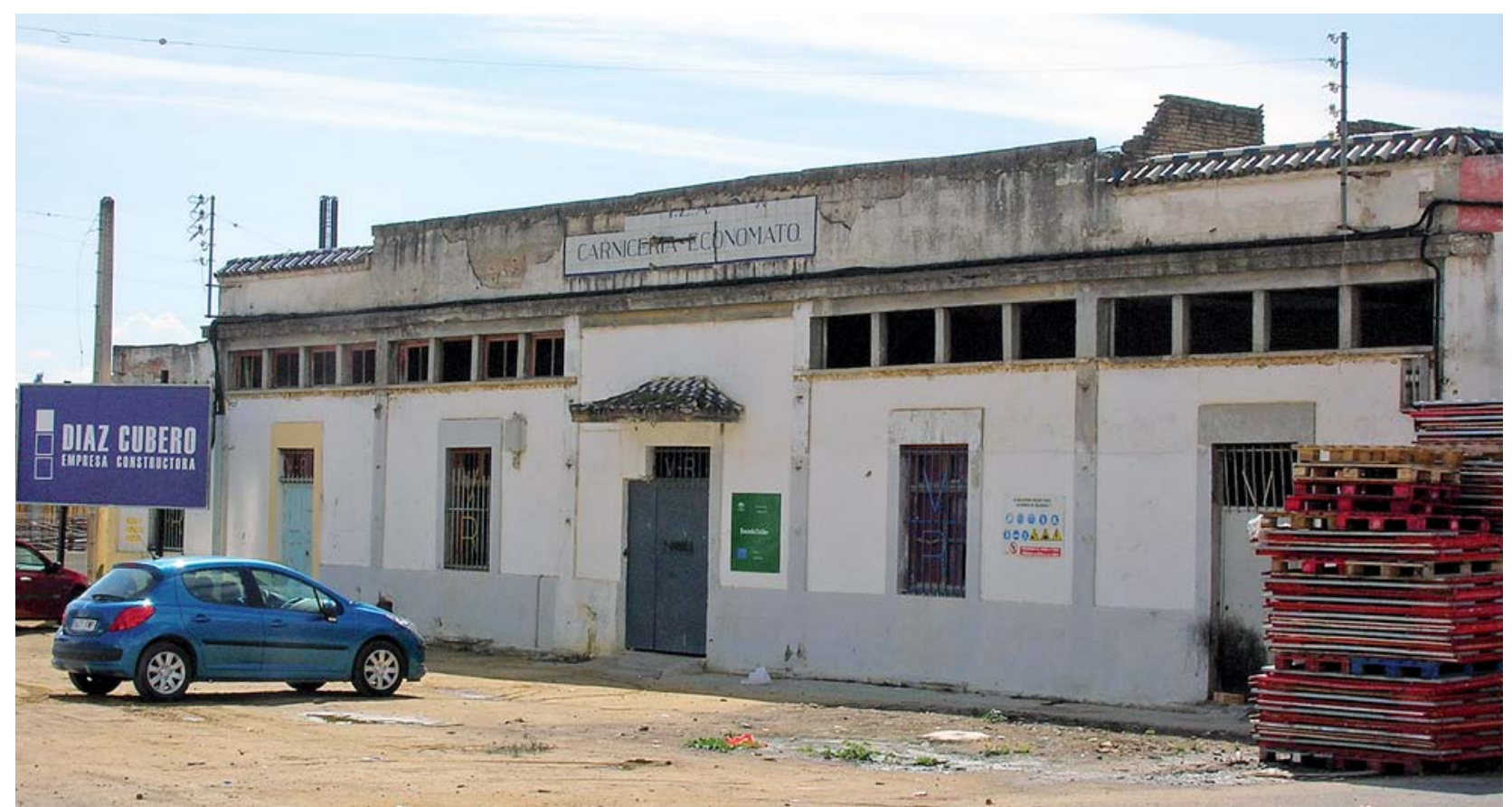

Fig. 2. Economato de la MZA en Villanueva del Río y Minas (Sevilla) (foto: autor) / MZA's company shop in Villanueva del Río y Minas (Seville, Spain) (author).

\footnotetext{
${ }^{3}$ Entrevista personal con M. Santofimia, directora del proyecto Minas de Sierra Morena. Los colores de la tierra (Eiffel Lab, 2013-2014).

${ }^{4}$ Entrevista con M. Santofimia.

${ }^{5}$ Un análisis acerca de la estación de salvamento de la SMMP durante el siglo XX en: COHEN et alii, 2006.
} 
raíces en la etapa preindustrial) constituye todo un modelo de vida saludable e higiénica, también en lo moral (vid. MENÉNDEZ-NAVARRO, 2012). Claro que el verdadero fin de todas estas iniciativas era recuperar fuerza de trabajo.

Igualmente importante para el capital fue disponer de una mano de obra instruida y capaz de asimilar los conocimientos técnicos necesarios para operar con las nuevas tecnologías importadas en la mina. Por ello, entre otros motivos, las escuelas proliferaron en las comarcas mineras, dando a sus pobladores un privilegiado acceso a la educación en el entorno rural de Sierra Morena. Generalmente separadas por sexo, muchas de ellas (Tharsis o La Zarza, en Huelva ${ }^{6}$ ) gozaron de buenas instalaciones y estuvieron perfectamente equipadas para ofrecer una enseñanza de calidad (CHASTAGNARET, 2000: 854-856).

Así y todo, no faltaron los poblados con índices culturales muy bajos, sobre todo allí donde la precaria economía de los hogares proletarios obligaba a los niños a interrumpir su instrucción para incorporarse al mundo del trabajo, tal y como ocurriera con frecuencia en Bédar -Almería- (SOLER y HANSEN, 2013: 76) o Puertollano (FERNÁNDEZ CALVO, 1987: 201) hasta principios del siglo XX. Esta circunstancia pudo fomentar el analfabetismo y ralentizar la difusión de las ideas políticas y sindicalistas, pero también propició la generación de un amplio número de mineros que necesitaban supervisión constante para realizar sus tareas.

\section{EL PUEBLO MINERO, CRISOL DE CULTURAS}

En términos generales, la configuración inicial de la comunidades minero-industriales estuvo marcada por el origen campesino de muchos de los trabajadores y por el carácter aislado de sus asentamientos -rasgos también presentes en el sur de la Península lbérica (vid. PEINADO y ANTA, 2010)-, lo que favoreció la proliferación del obrero mixto o campesino-minero (ARENAS, 2007: 122).

Por otro lado, en la construcción de este colectivo resultó determinante la ya mencionada fuerte movilidad de sus integrantes. Tanto es así que hasta aproximadamente la Primera Guerra Mundial los pueblos de las minas fueron, grosso modo, asentamientos de inmigrantes, caracterizados por la mezcolanza de sus gentes y su carácter plural, como puede apreciarse con claridad en la provincia de Huelva (AVERY, 1985: 231). Con todo, la composición de estos grupos humanos varió en función de cada caso. En Peñarroya, por ejemplo, durante el primer tercio del siglo XX convivieron obreros de varias provincias españolas, especialmente de Andalucía y Extremadura; también, de regiones más alejadas como Asturias, Galicia o País Vasco, junto con individuos de otras zonas mineras (Murcia) y países (vid. FLETA et alii, 2005).
Compartir cuarto en un cuartel o habitar en un hogar de reducidas dimensiones favoreció que el minero desarrollara su vida social en el escenario público. Escapaba así del hacinamiento de algunos enclaves decimonónicos, al tiempo que fomentaba la convivencia y el sentido de unión. Por otro lado, los espacios de socialización mostraron una clara sectorización por géneros: hombres en casinos, bares y tabernas; mujeres en el mercado o el hogar.

Como cabe suponer, no es posible definir un único patrón que sirva para describir al conjunto de estos hombres. Según la percepción del clérigo inglés en Linares H.J. Rose, los mineros andaluces del siglo XIX eran gente tosca -pero generosa e ingeniosa-, honesta, educada, trabajadora, alegre, de modesta estatura, poco amiga de la política y las agitaciones, y mucho de la compañía, el cante y el baile. Con una calidad de vida sensiblemente inferior a la de sus vecinos ingleses, carecían de capacidad para el ahorro, vivían al día y se regían bajo el lema "una vida corta y feliz", aunque no siempre conseguían aliviar sus penas o salvar sus dificultades (COLECTIVO PROYECTO ARRAYANES, 2011: 318-322) (Fig. 3).

En las plantillas de las compañías mineras no resultó extraña la presencia de mujeres ${ }^{7}$ y muchachos, ocupados fundamentalmente en tareas de exterior a cambio de un salario más bajo que el de los varones adultos. En otras ocasiones, la mujer reforzó la economía doméstica por cuenta propia, preparando comidas para los mineros o prestando otros servicios. Pero la mujer en la mina fue por encima de todo la esposa del minero, la administradora de una casa modesta y la madre de una familia numerosa (CARLONI, 2006: 145). Su situación nunca fue fácil, sobre todo cuando caía sobre ella la desgracia de la viudez. La pérdida del marido -y del principal sueldo- dejaba el hogar en una situación delicada, lo que en las clases más bajas podía suponer traspasar el umbral de la pobreza (PEINADO y ANTA, 2010: 418). Algo que añade más drama, si cabe, al triste paisaje femenino de las cuencas mineras, donde las viudas jóvenes (de 30 o 40 años de edad) y sus pequeños huérfanos fueron frecuentes (MARTíNEZ CARRIÓN, 2005: 25).

Por otro lado, y a pesar de lo estipulado por la Ley de condiciones de trabajo de mujeres y niños de 1900, el empleo de mano de obra infantil fue habitual hasta bien entrado el siglo XX (INSTITUTO DE REFORMAS SOCIALES, 1910: 95; HERNANDO y HERNANDO, 1999; PÉREZ DE PERCEVAL y LÓPEZ-MORELL, 2007: 30; MARTÍNEZ CARRIÓN, 2007: 244-249). En algunos casos, los niños ${ }^{8}$ se incorporaban al trabajo a partir de los 9 años de edad, encargándose -normalmente hasta los 16- de tareas como el transporte, el vaciado de vagonetas o la selección del mineral; o bien servían de ayudantes a los adultos (MAR-

\footnotetext{
${ }^{6}$ Entrevista con M. Santofimia.

7 Una visión genérica sobre el rol de la mujer en la mina puede leerse en: CARLONI, 2006; o HERNANDO y HERNANDO, 1999. A este respecto, las bal-maidens córnicas constituyen un buen referente (vid. PALMER y NEAVERSON, 1994: 77; MAYERS, 2009).

8 Una revisión sobre el papel y la vida del niño en las minas de Cartagena - La Unión en: GONZÁLEZ VERGARA, 2013.
} 

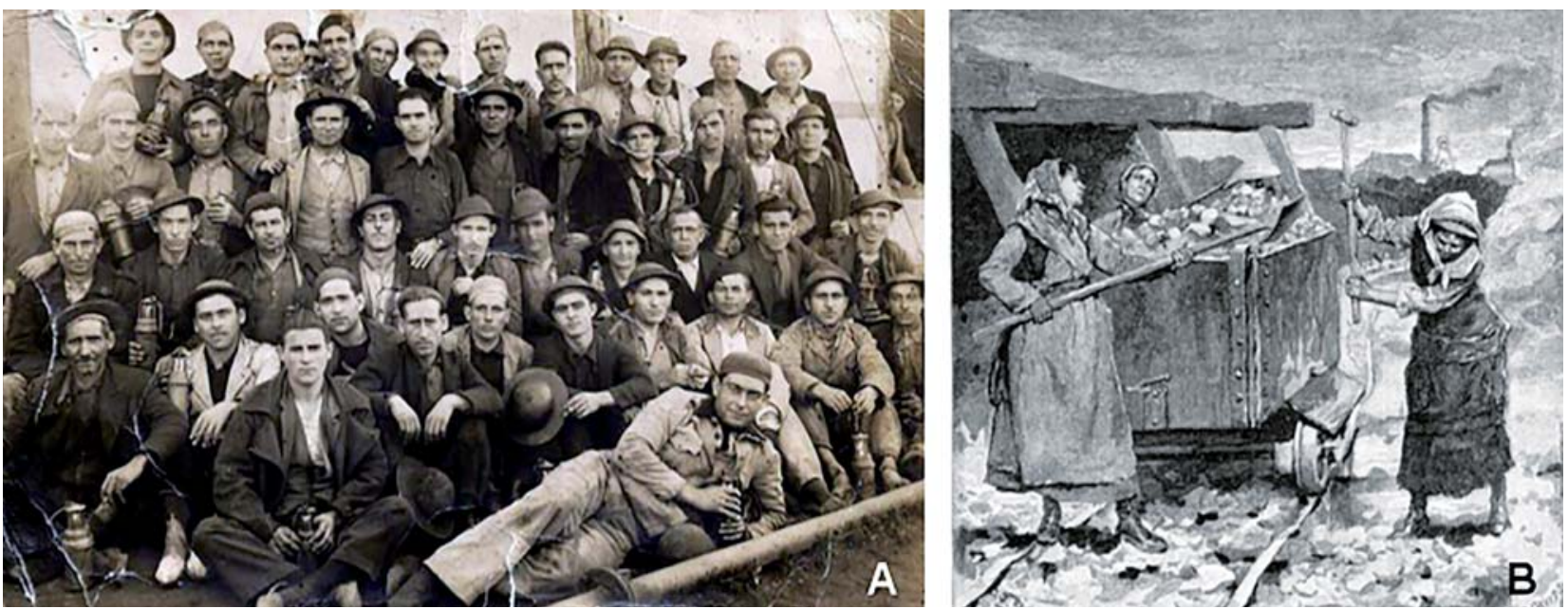

Fig. 3. A: Mineros de la SMMP en El Porvenir de la Industria (Fuente Obejuna, Córdoba) (colección Casto, vía http://aldeaelporvenir.blogspot.com). B: Un grupo de bal-maidens trabaja a bocamina en Carn Brea (Cornualles, Inglaterra) (MAYERS, 2009: 78, Fig. 16) / A: SMMP's miners in EI Porvenir de la Industria (Fuente Obejuna, Córdoba, Spain) (Casto collection, via http://aldeaelporvenir.blogspot.com). B: Bal-maidens at work in Carn Brea (Cornwall, UK) (MAYERS, 2009: 78, Fig. 16)

TÍNEZ CARRIÓN, 2007: 244-249; SOLER y HANSEN, 2013: 76-77). En las minas del SE peninsular, donde los salarios eran algo más bajos, la elevada participación de niños (los muchachos almerienses, entre otros colectivos) en la actividad minera se explica, como decíamos, por la delicada situación económica de sus núcleos familiares (MARTÍNEZ CARRIÓN, 2005: 25-26).

\subsection{Vicio y violencia}

La mina también ha sido un lugar de sometimiento y maltrato. Numerosos testimonios reflejan las duras condiciones de trabajo de los mineros. Algunas voces hablan, incluso, de castigos físicos; recuerdo que aún late en Bédar (vid. SOLER y HANSEN, 2013: 77), entre otros lugares. Sin embargo, ésa no fue la tónica dominante en las minas del sur peninsular, aunque no pueda negarse la presencia de la violencia.

La conjunción de un abultado número de jóvenes solteros (temporeros, inmigrantes, etc.) en los pueblos mineros fue, a menudo, el caldo de cultivo idóneo para todo tipo de altercados, especialmente cuando el juego y la bebida entraban en escena9. Las primeras generaciones de mineros bajo el mando de la Rio Tinto Co. Ltd. (RTCL) fueron especialmente conflictivas, consecuencia de su carencia de arraigo y de conciencia de grupo. En tal ambiente, los hurtos, las reyertas y los crímenes de sangre fueron algo cotidiano. El problema adquirió tal dimensión que buena parte de los despidos ejecutados por la RTCL en su primera etapa tuvo que ver con la bebida o con los delitos mencionados (AVERY, 1985: 186). Además, en Riotinto existió una importante desproporción entre el número de solteros y solteras, lo que contribuyó a que los pueblos de la cuenca se convirtieran en un buen filón para la prostitución (AVERY, 1985: 231).

El Linares del siglo XIX es otro buen ejemplo de comunidad minera moralmente degradada en la que abundan juego y prostitución, a veces con testimonios escalofriantes: ocasionalmente, cuando la necesidad apretaba, eran las propias madres quienes llevaban a sus hijas a las casas de citas (COLECTIVO PROYECTO ARRAYANES, 2011: 326). En aquel tiempo fue usual que los mineros dirimieran sus desencuentros en enfrentamientos violentos, mostrando con sus navajas un desprecio manifiesto por la vida que todavía es rastreable en dichos como "soy de Linares y pincho" o "de Linares, donde tres huevos son dos pares" (TORRES, 2011: 78) (Fig. 4). Lo mismo puede decirse sobre la Sierra Almagrera (Almería), donde las riñas entre mineros tal vez no fueron tan habituales, pero resultaron igualmente cruentas (SOLER y HANSEN, 2013: 77).

Allí donde concurrieron, estas circunstancias tensaron la convivencia entre la población local y la foránea. Los no autóctonos, percibidos como elementos disgregadores y socialmente desestructurados, fueron responsabilizados del clima general de hacinamiento, insalubridad, pobreza y delincuencia que el boom minero llevó a muchas cuencas (PEINADO y ANTA 2010, 419). La solución al problema se encontró en la familia, cuya llegada trajo sosiego e incluso un repunte de la producción (CARLONI, 2006: 145; vid. PÉREZ DE PERCEVAL y LÓPEZ-MORELL, 2007: 30; PEINADO y ANTA, 2010: 419). No sorprende, por tanto, que fuesen las propias empresas las primeras interesadas en facilitar a sus plantillas un verdadero hogar. De nuevo, Riotinto ilustra bien esta situación: a partir de la

${ }^{9}$ En Sierra Morena no fue extraño que el minero empezara el día con aguardiente -la popular palomita, mezcla de anís dulce y agua- y lo acabara con vino barato. 


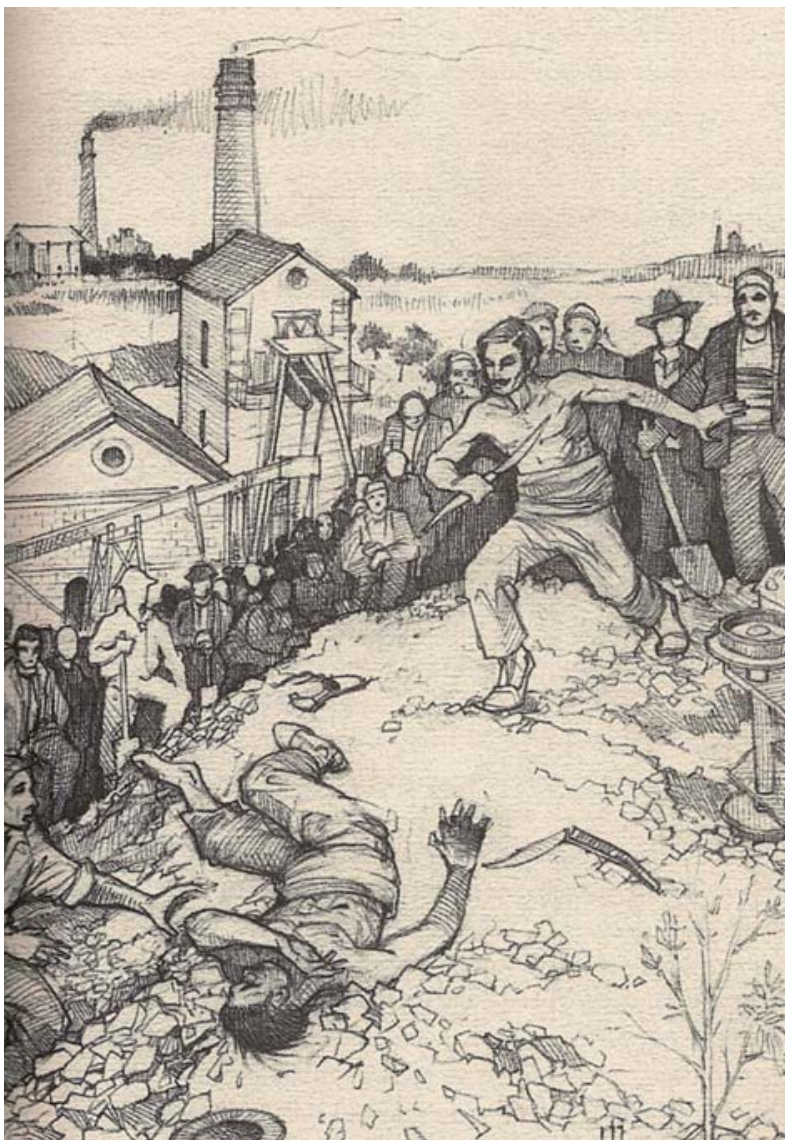

Fig. 4. Dos mineros se baten a muerte con sus navajas en una escombrera de Linares, Jaén (ilustración de A.J. Jerez García, en COLECTIVO PROYECTO ARRAYANES, 2011) / A pair of miners knife-fighting to death on a heap in Linares (Jaén, Spain) (illustration by A.J. Jerez García, in COLECTIVO PROYECTO ARRAYANES, 2011).

década de 1890, el programa de vivienda de la RTCL potenció el desarrollo de la vida familiar y consiguió relajar el ambiente al favorecer que la mayoría foránea enraizara y se identificara con el lugar (vid. AVERY, 1985: pp. 229-250).

\subsection{Extranjeros y colonos}

Frente al colectivo constituido por los mineros, las minoritarias comunidades extranjeras asentadas en las minas del sur peninsular presentaron unas características y estilo de vida muy diferentes. La gestión por parte de extranjeros de yacimientos españoles se hizo habitual a partir de la segunda mitad del siglo XIX, entre otras causas por el marco legal definido en 1868-1869 (vid. SÁNCHEZ PICÓN, 2005; CHASTAGNARET, 2007, p. ej.). Durante el boom minero los grandes nombres de la minería sureña pasaron a ser británicos y franceses (FERNÁNDEZ y GARCÍA, 2012: 3), sin olvidar la participación alemana, belga y de otros países ${ }^{10}$ ( vid. TORTELLA, 2000); ni tampoco el papel desempeñado por las compañías nacionales de ca- lado. No faltan, por tanto, ejemplos de áreas residenciales para grupos foráneos en dicho marco geográfico (Bella Vista en Riotinto, Pueblo Nuevo en Tharsis, el Barrio Francés de Peñarroya, etc.).

La manera en la que estas firmas extranjeras se relacionaron con los territorios explotados ha sido equiparada por R. Hernando y J. L. Hernando (1999: 72) con las inversiones de las grandes potencias económicas de nuestro tiempo en los países subdesarrollados, en el sentido de que la finalidad de unas y otras ha sido siempre la extracción de materias primas para su exportación. Es por ello que varios autores han tildado el fenómeno de "colonización económica", y a los centros mineros como "enclaves coloniales desconectados de su entorno" (SANCHEZ PICÓN, 2005: 18). Dichas "colonias", rastreables por buena parte del planeta, se configuraron a menudo como núcleos capaces de generar riqueza en medio de un contexto deprimido, del que se aislaron, tal y como sucedió en la provincia de Huelva (HARVEY y TAYLOR, 1987: 202). La mayor incursión británica en la minería peninsular, Riotinto, se ajusta bien a esta concepción, tanto a nivel económico como social (vid. AVERY, 1985).

A menudo, los integrantes de las cúpulas de estas compañías fueron personajes de cierta fama en su contexto. Varios ocuparon cargos políticos de relevancia (los vice-consulados británicos de Sevilla, Córdoba, Linares...), mientras que otros gozaron de reputación internacional: D. Shaw, R. Bonham Carter, G.D. Delprat, los hermanos Carr, E. Deligny, H.F. Collins (vid. MAWSON, 1958; VERNON y VERNON, 2007; CANO, 2012a) y un largo etcétera. Hubo también otros empleados extranjeros, un tanto más anónimos y pertenecientes a las clases medias de sus respectivos países de origen. Algunos acudirían al sur de la Península Ibérica sólo a solucionar problemas puntuales; otros para quedarse. Entre ellos hubo una importante representación de emigrados de Cornualles, como puede verse en Linares (vid. COLECTIVO PROYECTO ARRAYANES, 2011: 324 ss).

Aun cuando muchas veces se desarrolló un clima de una buena convivencia de los mineros españoles con sus jefes extranjeros, debió de existir una profunda distinción social entre la modesta clase obrera y sus superiores, reflejada, entre otros aspectos, en la arquitectura para la vida privada. El colectivo británico de Riotinto constituye uno de los casos mejor conocidos ( vid. AVERY, 1985, p. ej.), pero resulta un tanto excepcional en relación con otros lugares, especialmente aquellos donde el conjunto extranjero fue más reducido. En opinión de D. Avery (1985: 205), los ingleses no estuvieron interesados en buscar la integración en Riotinto, adonde llevaron sus costumbres -la celebración del cumpleaños de la Reina Victoria, entre otras- y una sociedad estructurada de manera piramidal en la que se reservaron la cúspide (CASTILLO, 2005: 385). De esta manera, se convirtieron en un grupo elitista y cerrado en un

${ }^{10}$ Sobre los ingenieros noruegos en las minas de Almería (Sierras de Almagrera, Bédar y Alhamilla), vid. SOLER y HANSEN, 2013. 
medio extraño, lo que no hizo sino marcar las diferencias y la incomprensión respecto a la población local. Dicho hermetismo acabaría pasando factura a muchas familias británicas, donde no faltaron casos de alcoholismo, excentricidad y depresión (vid. AVERY, 1985: 214 ss).

Reflejo material de esta situación, el barrio de Bella Vista aún se alza como una pequeña e idílica isla victoriana en un amplio territorio marcado por las cicatrices de la actividad minera a gran escala. Un espacio exclusivo de acceso vetado a los españoles (the natives) hasta 1931, cuando el Gobierno Republicano obligó a la RTCL a permitirles la entrada (AVERY, 1985: 324). No extraña, por tanto, que en la memoria colectiva de Riotinto aún perdure la condena al elitismo de la comunidad británica y a sus círculos sociales, que en general excluyeron de cualquier actividad que no fuese el trabajo a los españoles, si bien ello no fue siempre así (AVERY, 1985: 205-206). Este tipo de segmentación espacial entre las zonas de residencia de los mineros y sus jefes extranjeros (británicos, en este caso) se repitió igualmente en otros yacimientos de la comarca, como puede apreciarse en el Pueblo Nuevo de Tharsis o en el barrio de chalés de La Zarza (ROMERO, PÉREZ y PÉREZ, 2005).

A diferencia de lo ocurrido en la provincia de Huelva, en Peñarroya no existió esa ruptura entre españoles y fran- ceses; o al menos no fue tan acusada. Ello no quiere decir que no hubiera diferencias sociales, pero las jerarquías no las marcaba la nacionalidad, sino la clase y el rango laboral. Así, el Colegio Francés -inaugurado en 1902 por la congregación de las Hermanas de la Presentación de María- ofrecía educación (en lengua francesa) a los hijos de todos empleados, mientras que en el Círculo FrancoEspañol se admitía sin reservas a los altos cargos españoles (VERA, 2004). Lo mismo puede afirmarse de las viviendas construidas por la SMMP, distinguibles tipológicamente en función de la categoría laboral, pero sin diferenciar ni acotar zonas que separaran a la población francesa del resto (vid. LÓPEZ MOHEDANO, 2011) (Fig. 5). Un modelo, por tanto, diametralmente opuesto al británico de Riotinto, o al de tantas otras colonias industriales (mineras o no) repartidas por el mundo: piénsese, por ejemplo, en las plantaciones norteamericanas en Centroamérica (ELLIS, 1983).

\section{IDIOSINCRASIA}

Entender la idiosincrasia del minero español pasa necesariamente por conocer sus condiciones laborales. En el sur peninsular las compañías mineras implantaron varios sistemas de trabajo: por jornada (con salario fijo),

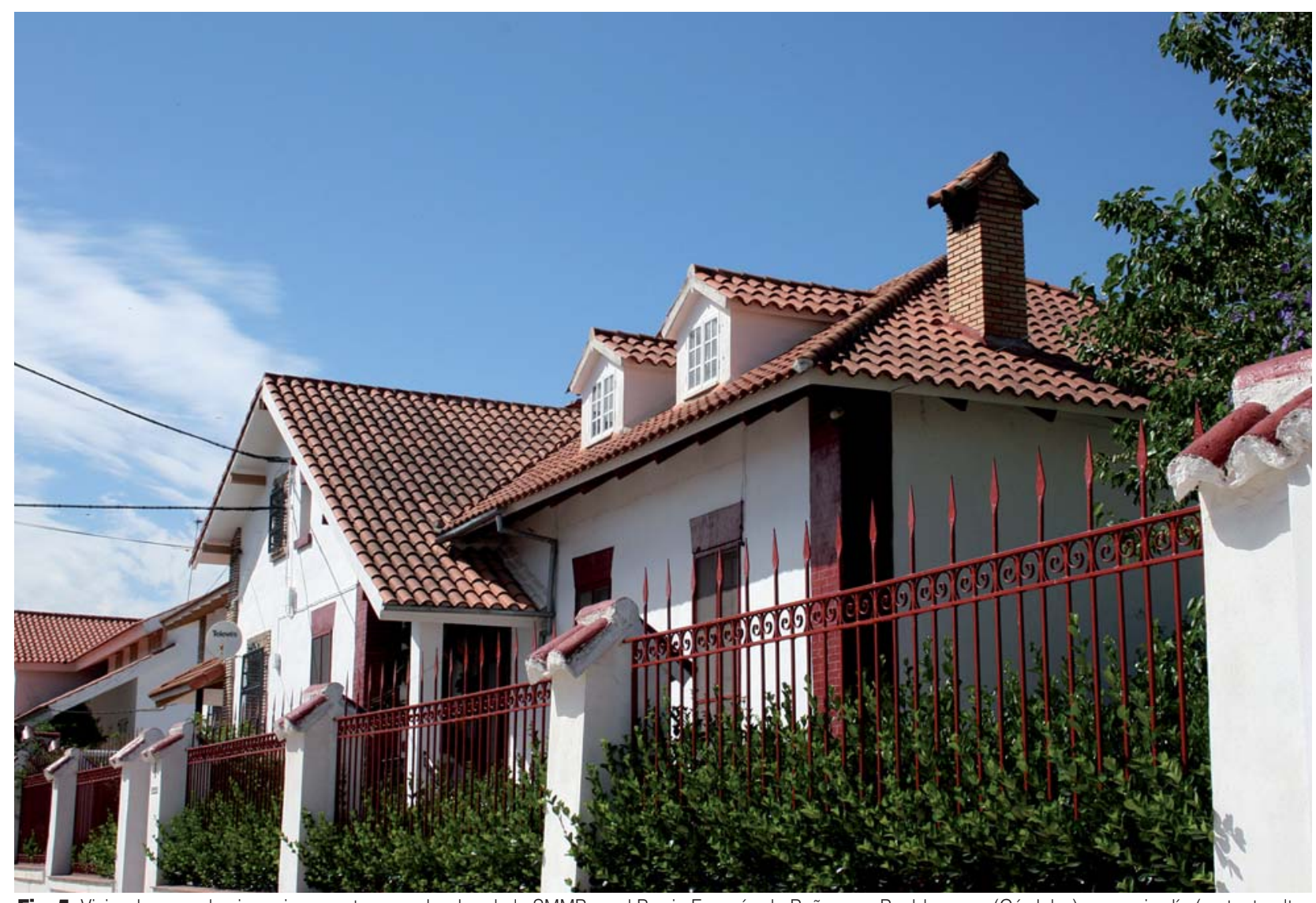

Fig. 5. Viviendas para los ingenieros y otros empleados de la SMMP en el Barrio Francés de Peñarroya-Pueblonuevo (Córdoba): casas-jardín (un tanto alteradas) en la calle Fábrica (foto: autor). / Housing for engineers and other SMMP's staff in the Barrio Francés of Peñarroya-Pueblonuevo (Córdoba): gardenhouses in Fábrica street (author). 
a destajo (a cobrar en función de lo trabajado) o por tareas (que implicaba que el obrero debía cubrir un determinado objetivo cada día, independientemente del tiempo que conllevara). Buena parte de los complejos minero-metalúrgicos estuvieron diseñados para funcionar 24 horas al día. A principios del siglo XX, la jornada laboral11 para los mineros de interior -así como para algunos trabajos en el exterior- era generalmente de 8 horas, sin incluir el tiempo invertido en el desplazamiento hasta el tajo. En los talleres, de sol a sol (12 horas), con descansos de 1-1,5 h en otoño-invierno y de 2-2,5 h en primavera-verano (INSTITUTO DE REFORMAS SOCIALES, 1910: 59; HERNANDO, 1989: 30). El día de descanso fue normalmente el domingo. Al menos, así estaba estipulado por la Ley de descanso dominical vigente desde 1904 (HERNANDO y HERNANDO, 1999: 79).

Tampoco hubo uniformidad en los salarios ${ }^{12}$, que variaban en función de la compañía y de la coyuntura económica nacional e internacional. En cualquier caso, en Sierra Morena el minero fue un trabajador mejor pagado que el agricultor, sin que ello implicara siempre ganar lo suficiente para vivir con holgura. El salario diario de un minero de la RTCL a mediados del siglo XIX rondaba los 15 reales, aunque podía alcanzar los 25 según su categoría; una cantidad nada desdeñable en relación con los 8 reales diarios que percibían de media las gentes del campo (AVERY, 1985: 187). A finales de dicha centuria, el jornal del minero de Linares era de unas 2,50 pesetas, mientras que los obreros del campo difícilmente lograban reunir dos (PEINADO y ANTA, 2010: 417).

Con todo, los mineros suribéricos podían considerarse mal pagados en comparación con los ingleses (BENSON, 1980), o bien en relación a la dureza y peligrosidad de su trabajo. Sin olvidar que la estabilidad del sueldo estaba condicionada -salvo cuando se disponía de buenos seguros y pensiones- por diversos elementos más o menos azarosos, como padecer un accidente o enfermedad (PEINADO y ANTA, 2010: 417).

\subsection{Movimiento obrero}

Las condiciones particulares de la mina (dureza del trabajo, inseguridad, etc.) y el acceso a la educación favorecieron la rápida difusión de las ideas socialistas, sindicalistas y anarquistas en numerosas cuencas mineras (vid. ARENAS, 2007). El movimiento obrero resultó especialmente vivo en los lugares con mayor concentración de mineros, como Riotinto (vid. AVERY, 1985). En otras zonas, en cambio, la escala de las explotaciones o su carácter aislado propiciaron un ambiente bastante más tibio, caso de las minas metálicas ubicadas en la provincia de Córdoba (HERNANDO, 1989: 56).
Hubo también veces en las que los sistemas paternalistas de las compañías se engranaron tan finamente con las asociaciones obreras que las tensiones entre patronal y proletariado fueron mínimas, o bien tendieron a resolverse con satisfacción para ambas partes, como a menudo ocurriera en Tharsis (ABC, 1933).

En términos generales, en las minas suribéricas el movimiento obrero fue una realidad poliédrica, compuesta por un buen ramillete de posturas diferentes e ideologías distintas: sindicatos, sociedades obreras, partidos políticos, anarquistas, etc. (vid. NUÑEZ DE ARENA y TUÑÓN DE LARA, 1979). En ocasiones, esta situación generó cierta falta de cohesión entre los trabajadores, divididos por sus ideas a pesar de compartir los mismos problemas. Así y todo, se cosecharon algunos éxitos. Destaca el caso de Eduardo Gómez, un metalúrgico que llegó a la Alcaldía de Puertollano en 1914, convirtiéndose, gracias a los votos de los sindicalistas y socialistas que ejercían de concejales, en el primer obrero en ocupar un cargo hasta entonces reservado a la oligarquía local; si bien no logró mantenerlo demasiado tiempo (FERNÁNDEZ CALVO, 1987: 204).

El sindicato fue la mejor arma de los obreros para defenderse y reclamar mejoras materiales; así como la huelga su principal instrumento. Éstas fueron recurrentes desde la segunda mitad del siglo XIX, aunque la mayor parte de ellas se disolvían con rapidez y escaso ruido. Los objetivos de estas reivindicaciones fueron variados (modificar las políticas de despido, implantar la jornada de ocho horas, reclamar mejores indemnizaciones para los accidentados y sus familias, etc.), aunque por encima de todos estuvo la subida salarial. Otras veces fueron ciertos problemas específicos los que movilizaron al proletariado, como los famosos humos de las teleras en Riotinto (AVERY, 1985: 183-190). Sea como fuere, el eco de las protestas y reivindicaciones mineras traspasó con frecuencia los límites de la mina, jugando -al igual que ocurriera en otros países, como Inglaterra, p. ej. (BENSON, 1980)- un papel decisivo en la conformación y desarrollo del movimiento obrero español (NUÑEZ DE ARENA y TUÑÓN DE LARA, 1979).

\subsection{Fe y superstición}

La fuerte presencia de la muerte en la vida del minero y una conciencia muy activa del otro mundo llevaron con frecuencia a estos hombres a confiar su suerte a santos y vírgenes, especialmente cuando la fortuna propiciaba un final feliz a los accidentes laborales. Ante la falta de una explicación razonable de lo ocurrido, la intervención de la Virgen fue una respuesta válida para muchos mineros (ORCHE, 2006).

\footnotetext{
11 Una completa revisión internacional de las diferentes jornadas en vigor a comienzos de la pasada centuria en: HERNANDO, 1989 : 25 ss. 12 Varias notas sobre los sueldos mineros en la España de principios del siglo XX en: HERNANDO, 1989: 34 SS; CHASTAGNARET, 2000: 837838, Tableau 127. Según el primer autor citado, los trabajadores de las minas no percibían más que los de otras industrias
} 
Simplificando la cuestión, podría decirse que el minero suribérico es sobre todo marianista, así como un activo participante en los eventos religiosos de sabor más popular, especialmente la Semana Santa. Pero si un culto sobresale por encima del resto en el mundo minero, ése es la devoción a Santa Bárbara -muy activo también en Alemania, p. ej. (SLOTTA, 2005)-, patrona de mineros, artilleros y fundidores de campanas (vid. AUTE, 2004: 288 ss). En Sierra Morena es rastreable en la práctica totalidad de las poblaciones mineras: Peñarroya-Pueblonuevo, San Nicolás del Puerto (Sevilla), Villanueva del Río y Minas, La Zarza, Riotinto, Tharsis, Corrales (Huelva), etc. La fiesta de Santa Bárbara tiene lugar el 4 de diciembre, incluso en aquellos pueblos donde no es la patrona oficial (Peñarroya, por ejemplo). Se trata de un día de celebración y reivindicación de la cultura minera en el que actividades de diverso tipo se adornan (y preceden) con la detonación de artefactos pirotécnicos o pequeñas cargas explosivas tomadas de los polvorines (AUTE, 2004: 291-292).
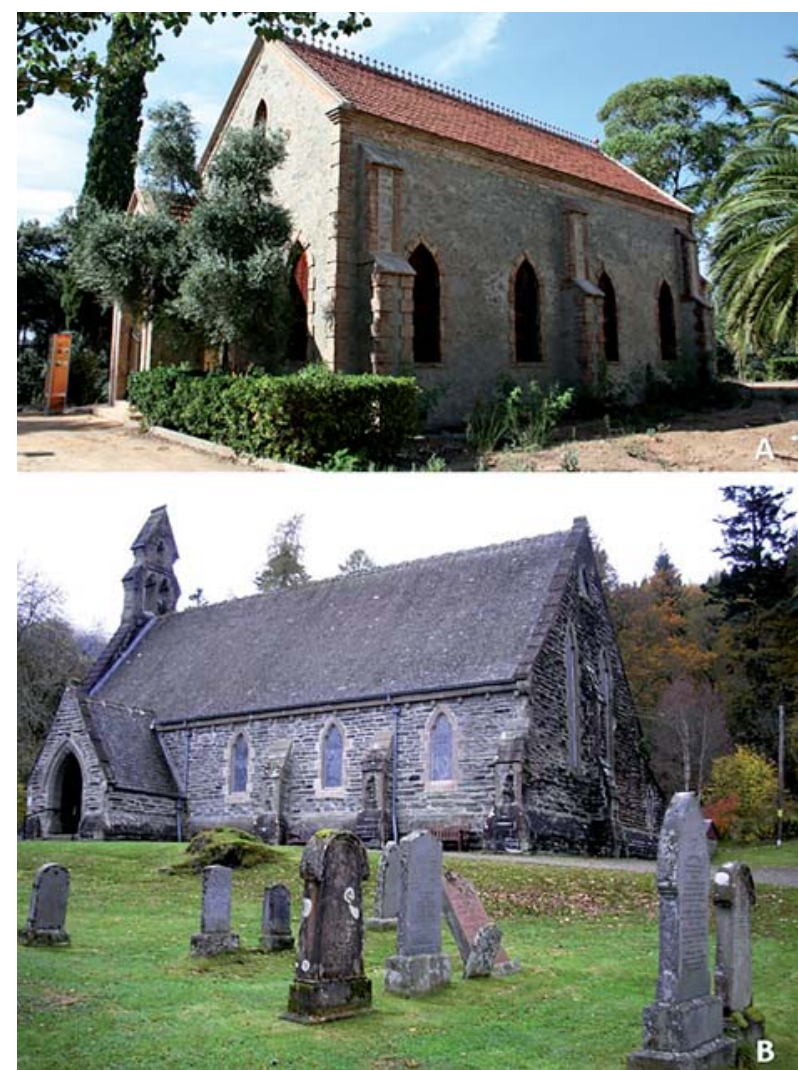

Fig. 6. A: Capilla Presbiteriana de Bella Vista, en Riotinto (Huelva) (foto: autor). B: Kirk en Balquhidder, Stirling, Escocia (foto: (๑) lain Lees, con licencia de reproducción Creative Commons) / A: Presbyterian chapel in Bella Vista (Riotinto, Huelva, Spain) (author). B: Balquhidder Kirk, Stirling, Scotland (source: @ lain Lees, licensed under the Creative Commons).
Toda el área minera del sur peninsular se encuentra salpicada de parroquias consagradas a Santa Bárbara: la de Peñarroya-Pueblonuevo fue construida por el consorcio malagueño Loring-Heredia-Larios en 1878 (AUTE, 2004: 291), mientras que la de Riotinto abrió sus puertas el año 1917, por citar un par de ejemplos de entre las que congregaron a más feligreses. Junto con las iglesias católicas, en los enclaves controlados por capital foráneo es frecuente encontrar también los templos levantados por la comunidad extranjera para el cumplimiento de sus respectivos credos, como el anglicano y el presbiteriano. En este sentido, destaca la Capilla Presbiteriana de Bella Vista (Riotinto), construida en 1891 al estilo de la kirk escocesa (DELGADO et alii, 2013: 91-92) (Fig. 6).

Aun cuando el templo suele ser, por definición, el espacio específico de la religión, en los enclaves mineros la fe se vivió en un conjunto mucho más amplio de escenarios, la mayor parte de ellos de carácter público y abierto. Prueba de ello son las varias manifestaciones religiosas que han llegado a nuestros días integradas en la tradición de las comarcas mineras: la Esquila en Riotinto ${ }^{13}$, la procesión del Cristo de los Mineros en Peñarroya, la Virgen de la Mina en Almadén, la Romería de Santa Bárbara en Tharsis, o las populares procesiones en honor de esta última figura bíblica (vid. AUTE, 2004: 292), entre tantas otras.

\subsection{Muerte}

El minero es un trabajador expuesto a la muerte. En su oficio debe afrontar un amplio conjunto de enfermedades y afecciones ${ }^{14}$, especialmente en las minas de carbón ${ }^{15}$, mucho más inestables y peligrosas que las metálicas. Entre las lesiones mortales más frecuentes en la primera mitad del siglo XX se cuentan los traumatismos (sobre todo de tipo cráneo-encefálico, producidos por hundimientos u otros golpes contundentes), las quemaduras (muchas de ellas derivadas de explosiones), la electrocución o la asfixia. El catálogo de enfermedades potencialmente letales incluía silicosis, pneumonía gripal, tuberculosis, enfisema pulmonar, lesión cardíaca, saturnismo (intoxicación por sales de plomo), hidrargirismo (envenenamiento por mercurio), anquilostomiasis, gastroenteritis crónica y otros problemas derivados de una alimentación pobre y desequilibrada (vid. COHEN et alii, 2006; MARTíNEZ y MENÉNDEZ, 2006: 147).

La frágil salud de los mineros y la dramática situación derivada de este hecho puede rastrearse en numerosos enclaves. Por ejemplo, en el Linares de principios del siglo $\mathrm{XX}$, cuyas calles, después de medio siglo de desarrollo económico, eran ocupadas por decenas de hombres im-

\footnotetext{
${ }^{13}$ Vid. INCUNA: Plataforma digital de los paisajes mineros españoles, http://mineriaypaisaje.com/rio-tinto-ic/.

${ }_{14}$ Para una revisión del marco legal en torno a los accidentes laborales y las enfermedades derivadas del trabajo minero -especialmente la silicosis-, véase MARTíNEZ y MENÉNDEZ, 2006.

${ }_{15}$ Un par de estudios sobre la siniestralidad en las cuencas carboníferas de la provincia de Córdoba en: HERNANDO y HERNANDO, 1999; COHEM et alii, 2006.licosis-, véase MARTíNEZ y MENÉNDEZ, 2006.
} 
pedidos para el trabajo o marcados por éste, triste sombra de los ausentes y gris compañía para las jóvenes viudas (PEINADO y ANTA, 2010: 418).

Diseñados como arquitectura específica para la muerte, los cementerios de las comarcas mineras reflejan su paisaje social. Ciertamente extraños en el territorio andaluz, destacan los camposantos ingleses de Tharsis, Riotinto o Linares $^{16}$ (Fig. 7), donde la recurrente fórmula epitáfica "in the loving memory" funciona como una marca territorial que diferencia el espacio de dos comunidades también separadas en vida (DOMÍNGUEZ, 2013). El cementerio de San Jorge, en Pueblonuevo (Peñarroya-Pueblonuevo), constituye un caso diferente: allí, españoles y franceses compartieron su última morada (VERA, 2004).

\section{VIDA COTIDIANA}

\subsection{Moda}

En las comarcas mineras del sur peninsular los atuendos destacaron por sus coloridos chillones y pintoresquismo, así como por su variedad, pues los mineros emigrados frecuentemente mantuvieron sus ropas locales

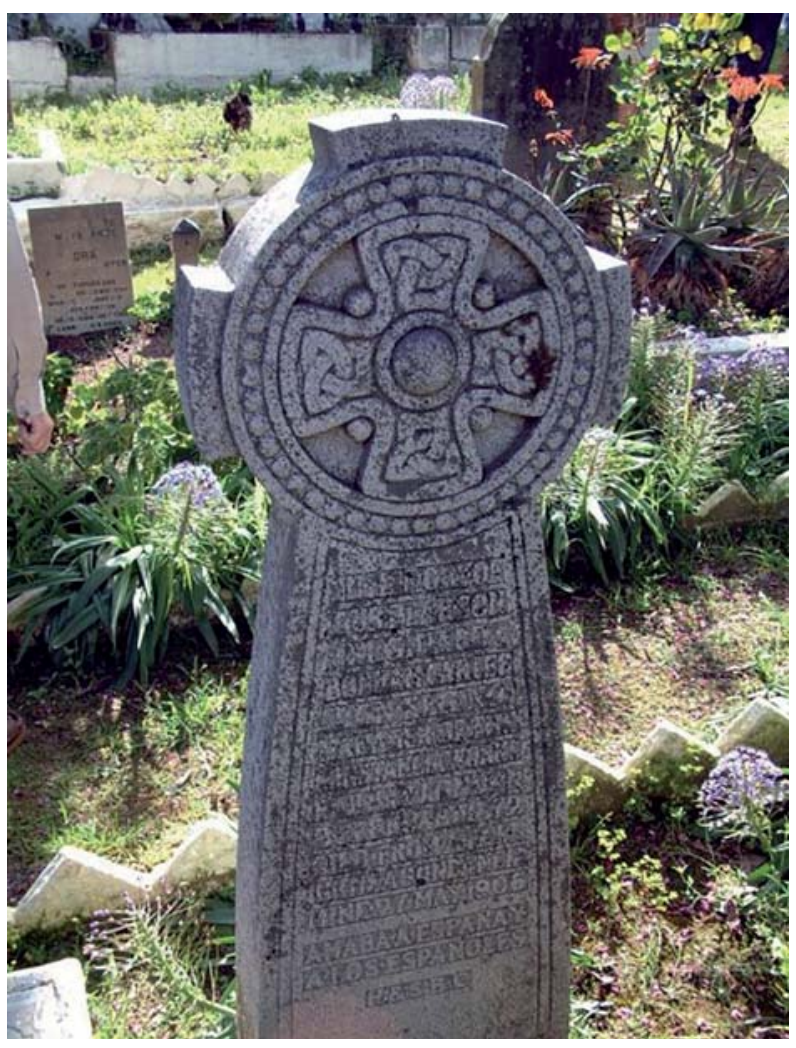

Fig. 7. Lápida de Reginald Bonham Carter en el cementerio protestante de Linares, Jaén (VERNON y VERNON, 2007). / Gravestone of Reginald Bonham Carter in the Protestant cemetery of Linares (Jaén) (VERNON y VERNON, 2007). y maneras de vestir, otorgando profundidad al armario del pueblo minero y generando un conjunto muy animado desde el punto de vista formal (COLECTIVO PROYECTO ARRAYANES, 2011: 260-263). A ello hay que sumar las modas importadas por la más acomodada población extranjera al mando. En algunos casos, el vestido funcionó como elemento de diferenciación social: piénsese en las mujeres inglesas de Riotinto o Cerro Muriano. En otros, las tendencias de estilo venidas de fuera tuvieron una fuerte influencia en la población autóctona, como ocurriera en Peñarroya con la popularización de lo francés (ropa, complementos, peinados, etc. $)^{17}$.

Caso aparte es el constituido por los atuendos de trabajo, que evolucionaron a la par que los avances en la industria textil y las medidas de seguridad e higiene. Hasta bien entrado el Novecientos, en Riotinto los hombres acudían al trabajo con un mandil de cuero abierto que se ataba a las rodillas, protegiendo sus cinturas con el uso de fajas. En las mujeres lo habitual eran las faldas de gran volumen y los delantales (AVERY, 1985: 237-238); nada que ver, por tanto, con la indumentaria laboral de las coetáneas mineras japonesas, que apenas se limitaba a un paño enrollado alrededor de la cintura que dejaba el torso al descubierto (Fig. 8).

Más allá de la ropa, durante el siglo XIX la dieta (pobre) y el padecimiento de determinadas enfermedades marcaron la configuración física y aspecto de los mineros, que en el sur de la Península Ibérica fueron, en términos generales, hombres de mediana estatura (vid. MARTÍNEZ CARRIÓN, 2005).

\subsection{Gastronomía}

Definir unas pautas generales que describan el conjunto de la gastronomía de los pueblos mineros no es tarea fácil, pues fueron los recursos de cada territorio los que marcaron la dieta de sus habitantes. Del mismo modo, es necesario distinguir entra la alimentación cotidiana de los mineros de la industrialización de aquello otro que, filtrado, ha llegado a nuestros días como cultura gastronómica de las cuencas. Destacan, en relación con este último aspecto, algunas recetas tradicionales (si bien no en todos los casos se puede hablar con garantías de un origen minero para las mismas): las gachas de Belmez, la caldereta de Santa Bárbara en San Nicolás del Puerto (Sevilla), o el potaje de Santa Bárbara en Villanueva del Río y Minas.

La alimentación del minero industrial en la Península Ibérica meridional fue, en general, un tanto escasa y poco variada, a pesar del desgaste físico que implicaba su trabajo. Estas dietas pobres en nutrientes, junto con un elevado consumo de tabaco y alcohol, tuvieron un efecto negativo en la población, muy expuesta, como ya hemos señalado, a complicaciones gastrointestinales y otras en-

\footnotetext{
${ }^{16}$ Sobre este último, vid. COLECTIVO PROYECTO ARRAYANES, 2011: 444 ss.

${ }_{17}$ Película documental La Madre. Una historia de colonialismo industrial (La Chimenea del Terrible, 2012, 50'). Una reseña en CANO, 2013.
} 

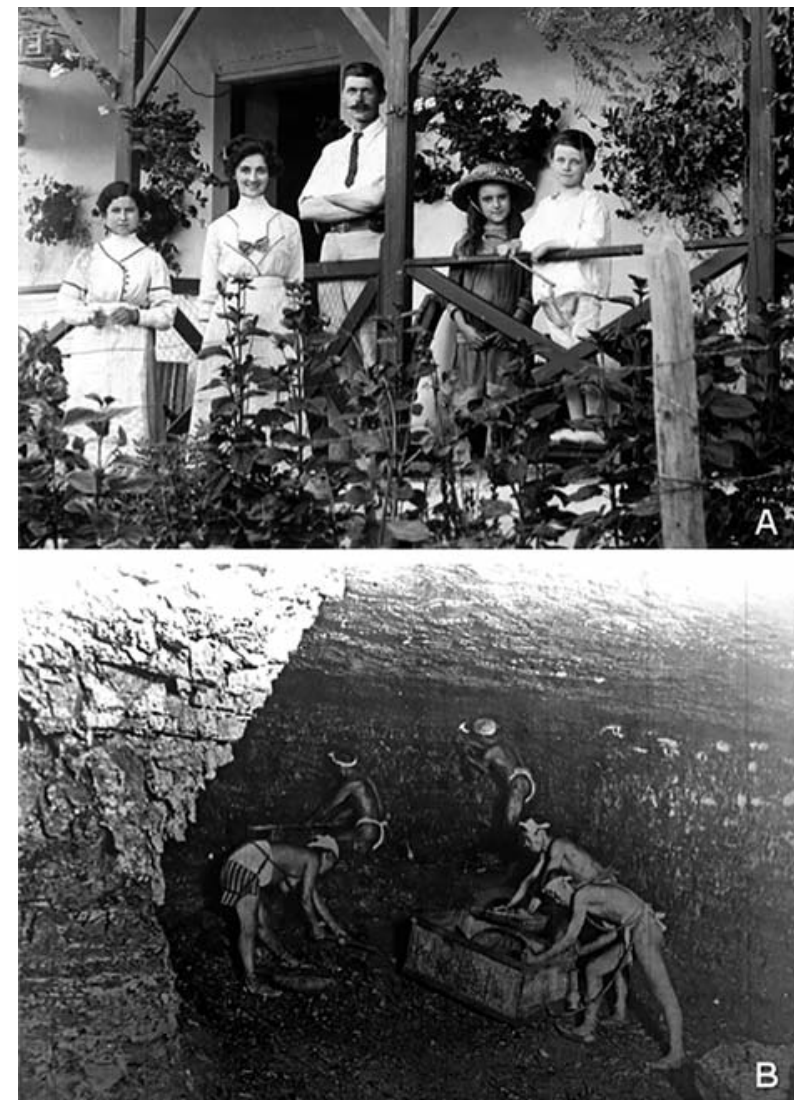

Fig. 8. A: Moda inglesa en el Cerro Muriano (Córdoba) de la década de 1910 (colección Pearce). B: Atuendo de los mineros japoneses (mujer y hombres) en una instantánea de 1910 (@) fondos del Deutsches BergbauMuseum). / A: English fashion in Cerro Muriano (Córdoba) in the 1910's (Pearce collection). B: Working clothes for men and women taken in a Japanese mine in 1910 (C Deutsches Bergbau-Museum collection).

fermedades (MARTÍNEZ CARRIÓN, 2005: 31-33; SOLER y HANSEN, 2013: 77).

En Riotinto, entre finales del siglo XIX y principios del $X X$, la dieta de los mineros se basaba en alimentos sencillos. El almuerzo se hacía en la mina y consistía en algo de pan, una cebolla y una pieza de fruta (una naranja o una tajada de melón). Las cenas, en casa, solía protagonizarlas un guiso de verduras y tocino de cerdo o un plato de arroz y pescado; regado, en ambos casos, con vino barato. En las comidas especiales se consumía cerdo asado (AVERY, 1985: 236). Por su parte, la alimentación de los mineros jienenses incluía frutas, vino ligero y agrio, sopas, pan y fritos sabrosos. Para los habitantes de los barracones no era extraño compartir una cena de arroz con carne de cabra cocida (COLECTIVO PROYECTO ARRAYANES, 2011: 326). Mayor variedad encontramos en el Puertollano de principios del siglo XX, donde entre los productos consumidos por la población minera se contaban tocino, bacalao, garbanzos, habichuelas, café, aceite, arroz, patatas y sardinas (FERNÁNDEZ CALVO, 1987: 200). Finalmente, y sin ánimo de redundar en más ejemplos, la dieta de un minero decimonónico de la Sierra Almagrera se basada en fruta, verdura, pescado, algo (muy poco) de carne y, sobre todo, pan. Allí el aguardiente resultaba más popular que el vino, y era tomada incluso en el desayuno. El jamón y los huevos eran considerados un lujo, pero así y todo eran más frecuentes que la carne. En los meses de verano los higos chumbos eran muy populares, ya que podía cultivarse sin costo ni demasiado esfuerzo (SOLER y HANSEN, 2013: 77).

Buena parte de los alimentos consumidos por los mineros procedía de los antes mencionados economatos o mercados instalados en los poblados, a menudo controlados por la propia empresa y con precios relativamente ventajosos. También fue habitual la presencia de huertas y gallineros en las viviendas, que permitían a los obreros completar su despensa con hortalizas, huevos y carne de ave (ORTEGA, 2003: 72).

Un rasgo distintivo de la alimentación de los mineros respecto a otras comunidades vecinas fue su acceso a ciertos productos de importación gracias al ferrocarril, sobre todo a aquellos pertenecientes a la dieta de las poblaciones extranjeras: en Linares, por ejemplo, los mineros españoles bebían cerveza inglesa, que creían capaz de curar la tos, entre otras bondades (COLECTIVO PROYECTO ARRAYANES, 2011: 322). Consecuencia de tal circunstancia, Peñarroya disfruta hoy de una rica gastronomía con influencia de las cocinas extremeña, andaluza, francesa y alemana. Esta mezcolanza de recetas e ingredientes de distintos lugares es también rastreable en Almadén, donde la movilidad de los mineros llevó hasta sus mesas platos andaluces (ajoblanco), extremeños (migas) y castellanos (pisto).

Con todo, fueron las tradiciones de cada región y los productos de la tierra los que más peso tuvieron en la configuración de la gastronomía de las comarcas mineras sudpeninsulares, como parece demostrar el hecho de que el Cornish pasty ${ }^{18}$-receta muy popular entre los mineros ingleses (córnicos, más concretamente) que viajó con ellos a otros continentes, como América (SHORTRIDGE y SHORTRIDGE 1998)- no tenga presencia ni aparente influencia en el sur de la Península Ibérica.

\section{OCIO Y FOLCLORE}

El ocio es un elemento muy relevante en la vida del minero. En el caso de los solteros, la disponibilidad de dinero y la ausencia de cargas familiares aumentó el tiempo invertido en actividades de entretenimiento. Muchos campamentos disponían, además, de las instalaciones recreativas promocionadas desde el capital. Por otro lado, el ocio, como el trabajo, fue a menudo un lugar de encuen-

\footnotetext{
${ }^{18}$ Empanada mitad salada (almuerzo) y mitad dulce (postre) para ser comida en la mina (entrevista con M. Palmer, Profesora de Arqueología Industrial en la Universidad de Leicester).
} 
tro para las comunidades local y foránea. Se generaron asi unas costumbres y cultura que diferenciaron a los pueblos mineros del resto del territorio (COLECTIVO PROYECTO ARRAYANES, 2007: 72).

En el sur peninsular el casino fue, con frecuencia, el escenario natural para el ocio moralmente saludable, frente a ventorrillos, cafés-cantantes o prostíbulos. En cierta manera, muchos se crearon para poner coto al ambiente de vicio que dominaba numerosos poblados mineros. En el de Tharsis, estaba prohibido jugar por dinero más allá del importe de las consumiciones (Fig. 9). En ocasiones, como en Riotinto, fueron construidos por la propia compañía, que pretendía con ello ejercer cierto control sobre la cantidad de alcohol ingerida por sus trabajadores (AVERY, 1985: 204). En los casinos (con otros ejemplos en Peñarroya o Villanueva del Río y Minas) los asociados disponían de buenas bibliotecas, salones de baile y salas de juego y tertulia, sin olvidar los espacios para comer, beber y discutir (VERA, 2004: 391). En definitiva, todo lo necesario para desarrollar sus aptitudes sociales.

\subsection{Tiempo festivo}

Muchas de las fiestas características de las comunidades mineras guardan relación con el mundo laboral o de las creencias religiosas. Directamente vinculados al pri- mero, los concursos de entibadores siguen siendo usuales en varios pueblos con pasado minero (vid. AUTE, 2004: 293). Celebrados normalmente el día Santa Bárbara, se valora el mejor cuadro, no el tiempo de su ejecución; lo contrario sería una temeridad (Fig. 10).

Existen también festejos de carácter eminentemente lúdico, aunque con frecuencia enlazados de algún modo con los ámbitos del trabajo y la religión. Los bailes gozaron de una cálida acogida en las comunidades mineras; los dedicados a Santa Bárbara fueron del gusto de todas las clases sociales. Así lo vemos en el desenfadado Baile de los Peritos organizado por los estudiantes de la Escuela de Minas de Belmez, o en el convocado por la SMMP para sus altos cargos en el Círculo Franco-Español, de carácter más refinado (AUTE, 2004: 292). El carnaval es asimismo una celebración popular en el sur de la Península Ibérica, si bien sólo en unos pocos casos podemos hablar de fiestas de tradición minera: en La Zarza, por ejemplo, con su singular entierro de la pirita ${ }^{19}$.

Por su parte, el colectivo extranjero trajo consigo sus propias costumbres y sistemas de socialización. Los ingleses exportaron a España el té de las 5 pm y los boy scouts. En Riotinto, el ocio de la comunidad británica se concentró en el Club Inglés de Bella Vista -otra muestra en el barrio inglés de La Zarza ${ }^{20}$, marco de sus reuniones civiles y políticas más importantes. El salón del club acogió

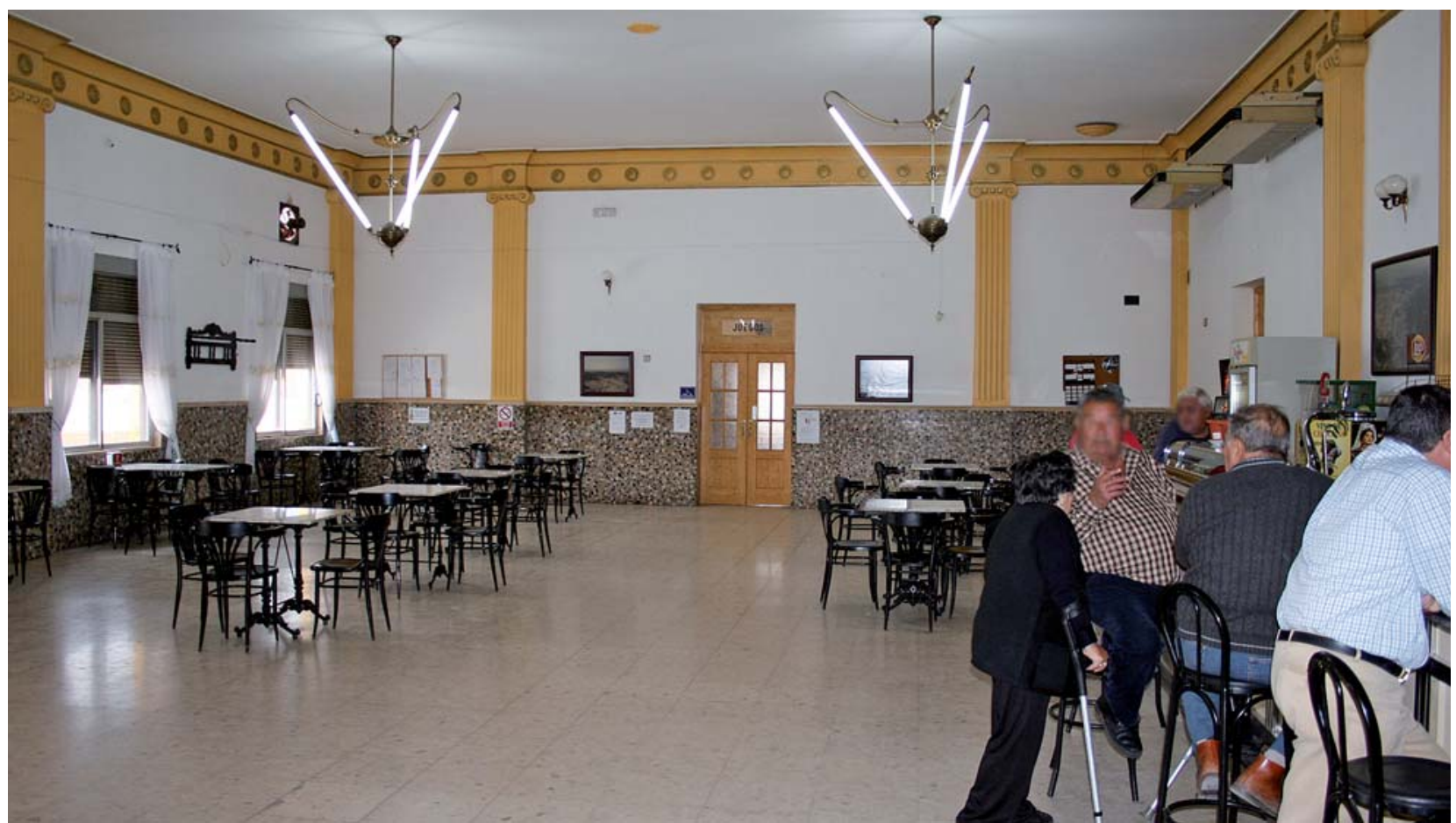

Fig. 9. Interior del casino -Círculo Minero Recreativo- de Tharsis (Huelva), aún en uso (foto: autor). / Leisure centre for the miners of Tharsis (Huelva), still in use (author).

\footnotetext{
${ }^{19}$ Entrevista con M. Santofimia.

${ }^{20}$ Entrevista con M. Santofimia
} 

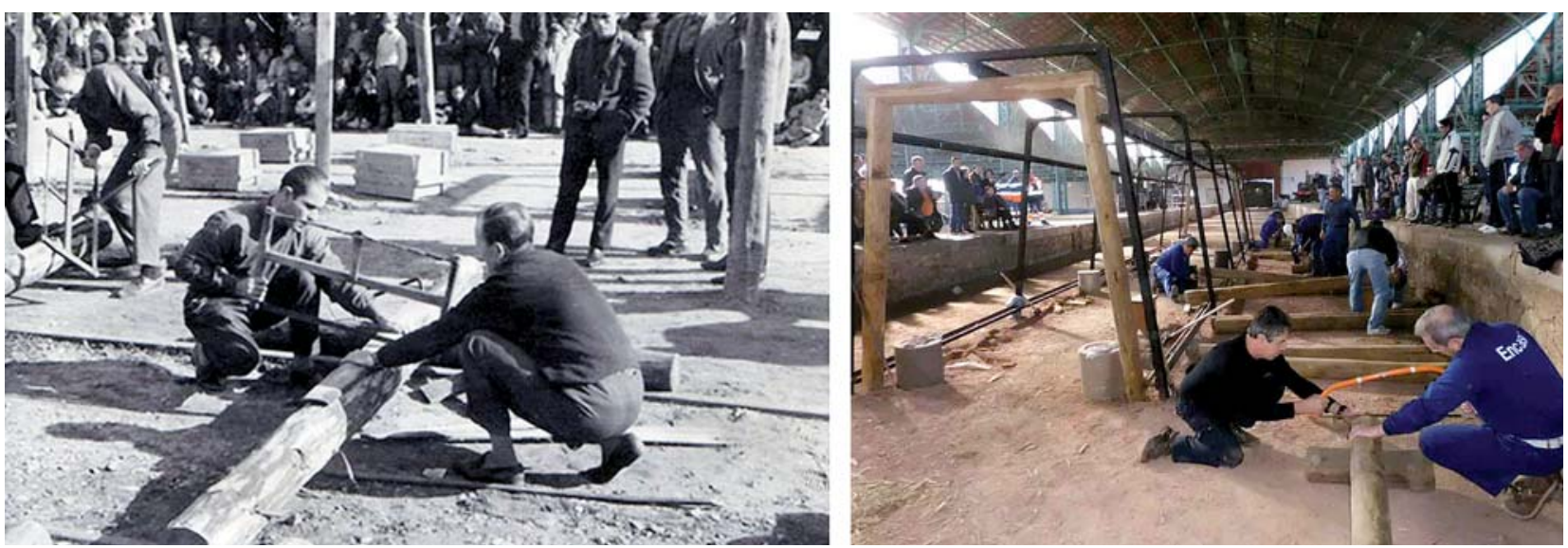

Fig. 10. Concursos de entibadores, ayer (izq.: Villanueva del Río y Minas, 1961; fuente: http://villanuevadelasminas.es) y hoy (dcha.: Peñarroya-Pueblonuevo 2013; fuente: http://infoguadiato.com). / Timbermen competition, past (left: Villanueva del Río y Minas, Seville, 1961; source: http://villanuevadelasminas.es) and present (right: Peñarroya-Pueblonuevo, Córdona, 2013; source: http://infoguadiato.com).

la celebración de numerosos bailes, a veces de disfraces: de Fin de Año, de Carnaval, de apertura y clausura de la temporada de verano (vigente), etc. También puestas de largo, cumpleaños, bautizos, bodas e iniciaciones en la religión presbiteriana (primeras comuniones, en la etapa española). El club estaba asimismo provisto de una biblioteca dotada con volúmenes en inglés y en español, aunque la principal lectura fue la prensa británica (para los caballeros) y las revistas de moda y corazón (por parte de las señoras). Otras actividades practicadas en el club eran la pintura, la música y el teatro (REGALADO, MORENO y DELGADO, 2010)

A pesar de lo dicho, el Club Inglés de Bella Vista fue básicamente una institución consagrada al deporte. Su legado sigue activo a través de la Sociedad Club Inglés de Bella Vista, que años después de la marcha de los ingleses mantiene parte de sus tradiciones: celebración del Father Christmas, baile de Fin de Año, campeonatos de billar y tenis, etc. (REGALADO, MORENO y DELGADO, 2010). Una manifestación clara y evidente del peso de la minería inglesa y sus implicaciones sociales en la conformación del contexto cultural sudpeninsular.

\subsection{Deporte}

Las cuencas mineras, especialmente las explotadas por capital extranjero, fueron la puerta de entrada a España para un buen número de deportes. En este sentido, el legado de los mineros ingleses a la cultura popular del país tiene en el fútbol una de sus principales contribuciones. Fueron los británicos desplazados a las minas andaluzas -onubenses, más concretamente- quienes introdujeron esta práctica deportiva en la Península lbérica (MARTÍNEZ CALATRAVA, 2001). El primer partido ofi- cial se jugó en España el 8 de marzo de 1890 en el Hipódromo de la Sociedad de Carreras de Caballos de Sevilla Se midieron Sevilla Football Club y Huelva Recreation Club, con resultado favorable de 2-0 para el equipo local; el vicecónsul británico en Sevilla hizo las veces de árbitro21.

El mencionado Club Inglés de Bella Vista contribuyó de manera efectiva y pionera a la difusión de los deportes británicos en Riotinto y, por extensión, en otras zonas del sur peninsular. Junto con el fútbol, la comunidad británica practicaba tenis, billar, squash, cricket, cróquet, bádminton, polo y golf22 (Fig. 11); incluso algunos deportes náuticos, aprovechándose el Dique del Zumajo. En un primer momento, el deporte estuvo relativamente restringido a la colonia británica, aunque pronto se popularizó en el resto de la población, especialmente el fútbol, el billar, el golf y el tenis (REGALADO, MORENO y DELGADO, 2010: 50; DELGADO et alii, 2013: 92).

Los deportes de tradición inglesa fueron, tal vez, los que más se extendieron por las cuencas. En Peñarroya, por ejemplo, también se jugaba al fútbol -se construyó un estadio con capacidad para 4.000 espectadores (LÓPEZ MOHEDANO, 2004: 187)- y al tenis, si bien en aquel lugar el baloncesto gozó asimismo de una afición que se ha mantenido hasta nuestros días.

\subsection{Música y otras manifestaciones artísticas}

En los poblados mineros más desarrollados la oferta cultural pudo verse completada con teatro y, ya en el siglo $X X$, cine, en muchos casos actividades promocionadas por las compañías y alojadas en edificios de su propiedad. Belmez contó con cines de verano y de invierno, mientras que los mineros de Corrales o Villanueva del Río y Minas, entre otros, consumían parte de su ocio en sus Teatro-Ci-

\footnotetext{
21 The Dundee Courier, edición del 17 de marzo de 1890.

22 Algunas notas descriptivas sobre la práctica de cada uno de estos deportes en el Riotinto inglés en: REGALADO, MORENO y DELGADO, 2010.
} 


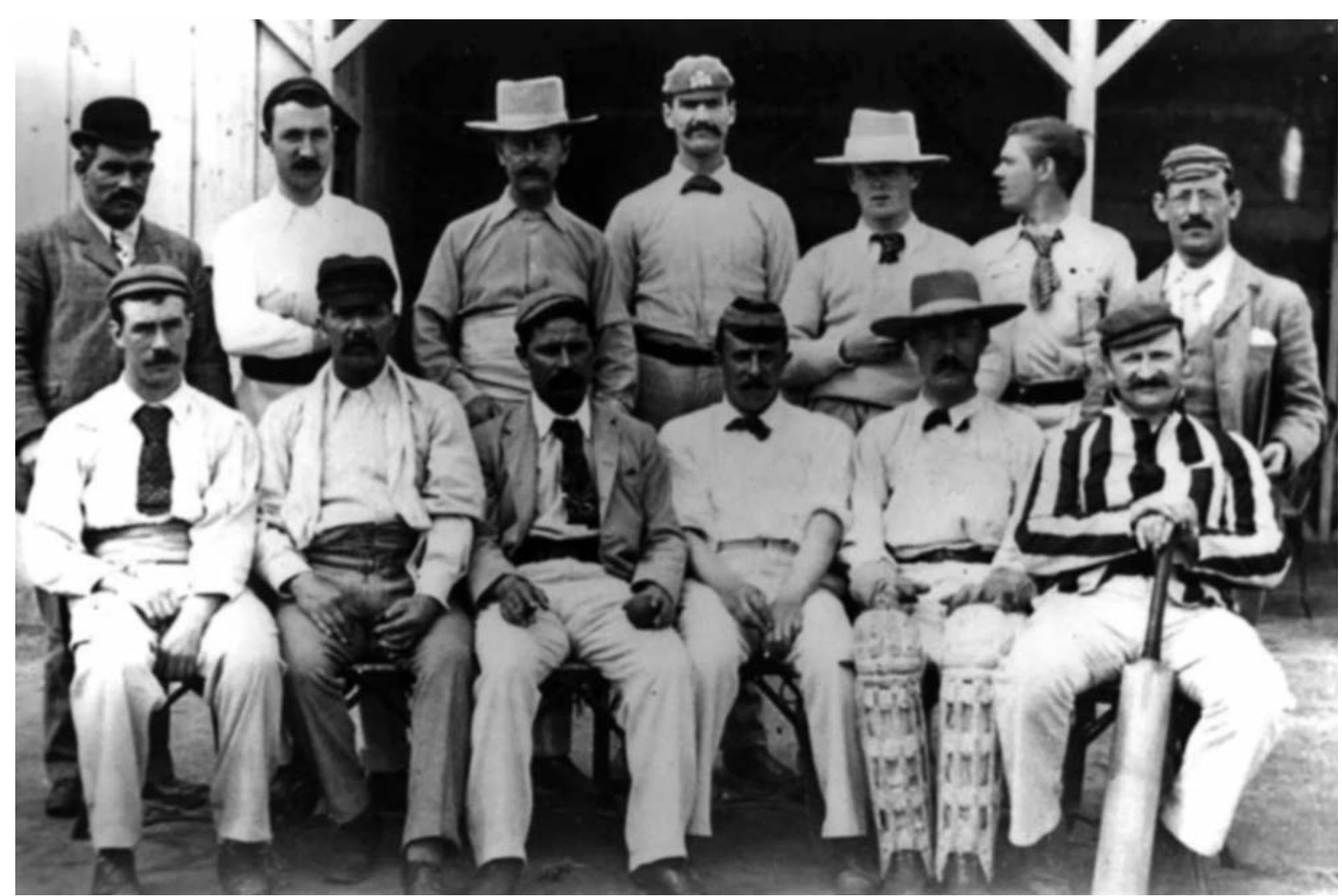

Fig. 11. Equipo de cricket de Riotinto (Huelva), en 1890 (foto: Archivo Fundación Río Tinto, en REGALADO, MORENO y DELGADO, 2010: 51, Fig. 8). / Cricket team in Riotinto (Huelva), in 1890 (source: Archivo Fundación Río Tinto, in REGALADO, MORENO y DELGADO, 2010: 51, Fig. 8).

nema (Fig. 12). Los peñarriblenses también pudieron disfrutar de su tiempo libre en el teatro o en alguna de las cuatro salas de proyección que llegaron a estar abiertas simultáneamente (LÓPEZ MOHEDANO, 2004: 187), algo de lo que ya no pueden presumir. Además, Peñarroya llegó a convertirse en un escenario importante en el panorama nacional y a acoger actuaciones de calado (Lola Flores, p. ej.) $)^{23}$. Otras veces, los espectáculos fueron protagonizados por los propios mineros. Así funcionaba el Salón-Teatro de Cerro Muriano, donde la sociedad Juventud Recreativa ofrecía sus representaciones (RAMOS, 1914: 5; ESTADÍSTICA MINERA, 1916: 184).

Por otro lado, la minería ha tenido sus propios sonidos -piénsese, en la Bergmusikkorps Saxonia Freiberg y el Bergchor alemanes; o en el Cante de Santa Bárbara de San Nicolás del Puerto o en la Canción del Carbón de Casariche, en la provincia de Sevilla-, un hilo musical variado en cuanto a estilo, pero de temática recurrente. Aun cuando las bandas musicales han sido un elemento muy común en la cultura popular española, en ciertos casos pueden asociarse con la actividad minera, como en
Huelva, donde aparecen ligadas a la tradición británica de la brass band. Destaca, en este sentido, la constituida en La Zarza en 1917 al amparo de la Tharsis Sulphur \& Copper Co, que otorgó ciertos privilegios a sus integrantes y la incorporó a sus propios protocolos. Como el Club Inglés de Bella Vista, se trata de otro activo cultural que ha sobrevivido al cese de la minería ${ }^{24}$

Pero si un estilo musical tuvo arraigo entre los mineros del sur peninsular, ése fue el flamenco, tal vez el vehículo más apropiado para canalizar y proyectar sus emociones. Los Cantes de Minas, en buena parte originarios de las comarcas mineras del sudeste, viajaron con los mineros a otras explotaciones, lo que contribuyó a que se diversificaran y enriquecieran con nuevos matices: fandangos, tarantas y tarantos en Almería; cartageneras, tarantas, mineras, fandangos mineros, levanticas y murcianas en Muricia; tarantas ${ }^{25}$ de Jaén; fandangos en Huelva; etc. En palabras de Navarro e lino (1989: 7), "los Cantes de las Minas son el fruto, por una parte, del sufrimiento minero, de la tragedia que cada día le acecha en las minas, y por otro, del sentimiento musical y del

\footnotetext{
${ }^{23}$ Documental La Madre. Una historia de colonialismo industrial.

${ }^{24}$ Entrevista con M. Santofimia.

${ }^{25}$ Sobre este palo en Linares, vid. TORRES, 2011. El trabajo incluye datos sobre Antonio Grau Mora (Rojo el Alpargatero: 1847-1906), considerado uno de los padres de los cantes mineros.
} 


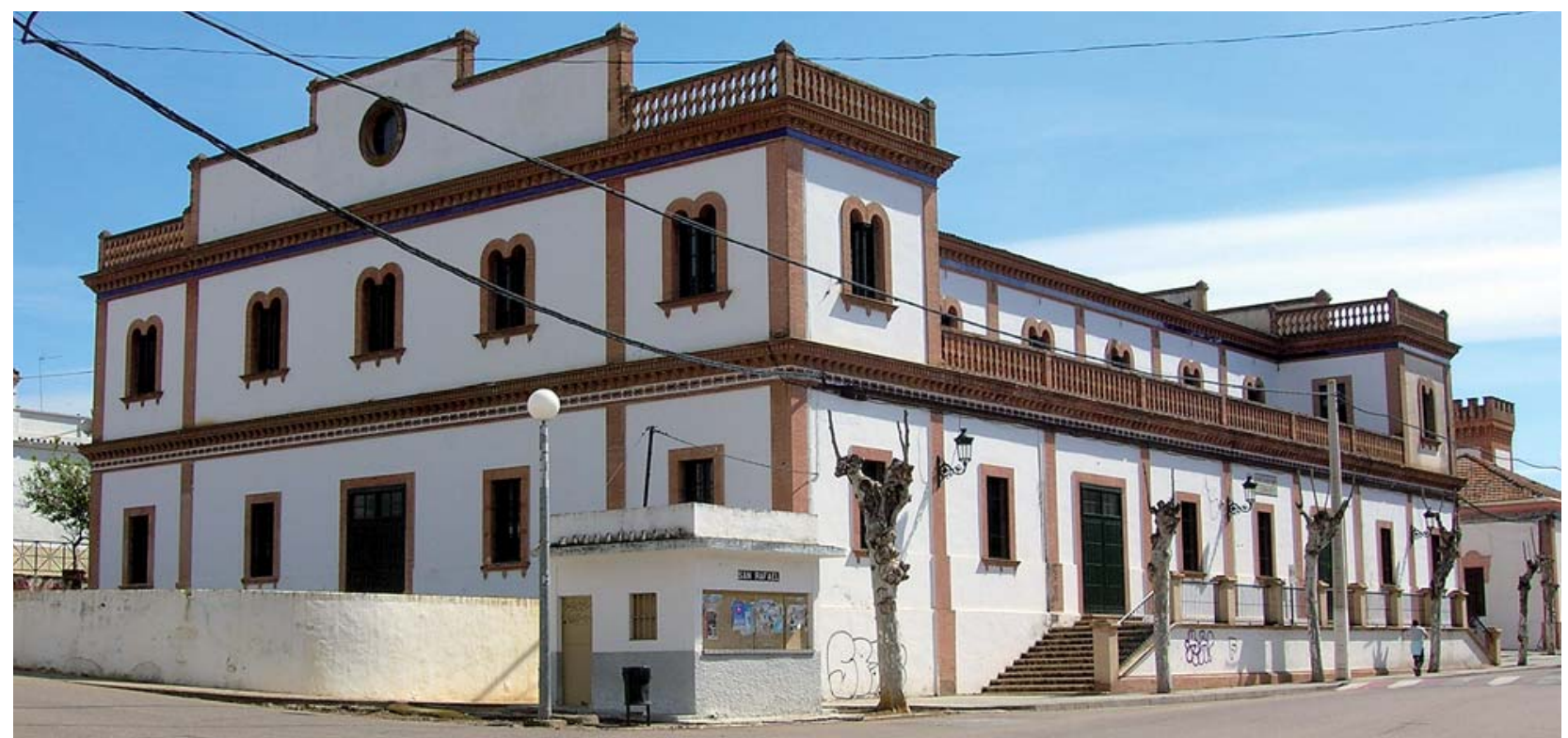

Fig. 12. Teatro-Cine de la MZA en Villanueva del Río y Minas (Sevilla) (foto: autor). / MZA's Teathre-Cinema in Villanueva del Río y Minas (Seville) (author)

magisterio de una serie de cantaores profesionales que han ido puliendo sus interpretaciones hasta conformar estilos que han llegado hasta nosotros".

Estos cantes reflejan el sentir de los mineros -sus miedos, sus creencias, sus anhelos, sus pasiones...- y el ambiente en el que desarrollaron sus actividades, lo que hace de ellos una fuente de información muy interesante para comprender tanto el contexto cultural generado por la minería -confrontación social, movimiento obrero, perfiles de mineros y empresarios, etc.- como también algunos aspectos más técnicos: herramientas y métodos de trabajo, clasificación laboral, sistemas de transporte, etc. (vid. GONZÁLEZ VERGARA, 2012). Entre los temas más habituales se repiten la alusiones a la oscuridad, el frío y la muerte. Es una característica común su tono general de amargura y tristeza, a veces subrayada por la soledad del minero en el interior de la mina. Emociones que, a menudo, son catalizadas por la fe. También se canta al amor, muchas veces desde la perspectiva pesimista de la viuda o la madre; y a la violencia. No faltan en estas letras argumentos más mundanos, como la diversión encontrada por los mineros en el alcohol despachado en los locales de ocio (TORRES, 2011; GONZÁLEZ VERGARA, 2012).

El cante minero salió de los pozos para instalarse en las tabernas, los ventorrillos y, sobre todo, los cafés-cantantes, lugares en los que convivió con el juego, la bebida y la prostitución. Estos factores favorecieron su desprestigio inicial y evolución como subcultura, hasta su popularización y llegada a los teatros y artistas profesionales, ya avanzado el siglo XX (TORRES, 2011: 76; GONZÁLEZ VERGARA, 2012: 60-63). Consolidado como una manifestación cultural genuina y distintiva, el cante minero sigue vivo, latiendo con fuerza cada año en citas como el Festival Internacional del Cante de las Minas de La Unión (Murcia) o el Concurso Nacional de Tarantas de Linares$^{26}$ (Jaén).

"Era un niño todavía ganando su primer jornal pero nadie lo creía

por lo serio y lo formal que en la mina iba y venía"

Cante minero de La Unión (GONZÁLEZ VERGARA, 2013)

\section{CONCLUSIONES}

El sur de la Península lbérica es una de las áreas con mayores y más variados recursos minerales de todo el sudoeste europeo (vid. ENADIMSA, 1986: 109). No sorprende, por tanto, que las actividades extractivas hayan desempeñado un rol fundamental en la evolución social y económica de dicho territorio desde tiempos prehistóricos (vid. PUCHE, 2001) hasta la actualidad (vid. SÁNCHEZ PICÓN, 1997), participando incluso en la fundación de algunos de sus núcleos urbanos más importantes (vid. VENTURA, 1993; VAQUERIZO, 1994; PENCO, 2010). La industria minera ha sido, por tanto, un agente activo en la configuración de muchas de las poblaciones asentadas en dicho marco geográfico, dejando en ellas una impronta que aún hoy, años después de la desactivación del sector, es posible rastrear.

${ }^{26}$ Sobre el mismo, que se celebra desde 1963, vid. TORRES, 2011: 79. 
A ello contribuyeron de manera especial el paisaje generado por la minería -que a menudo dejó espacio sólo para una agricultura y ganadería marginales (SANTIAGO, 2004: 282)- y la activa presencia inmigrante, que incorporó al contexto cultural de las zonas mineras contemporáneas (y también al de otras etapas históricas) un buen número de tradiciones y creencias exógenas. Elementos ciertamente extraños en un entorno rural y atrasado, en el que la propia comunidad minera nacional también se constituyó como un colectivo diferenciado (vid. AVERY, 1985: 229-230).

Por otro lado, la mina ha sido descrita con frecuencia, y no sin motivos, como un escenario de sufrimiento y confrontación (SOLER y HANSEN, 2013). En cambio, y como hemos tratado de reflejar en las páginas precedentes, no es menos cierto que los habitantes de los asentamientos minero-industriales gozaron asimismo de ciertos privilegios. Sin entrar en el debate sobre la repercusión real (positiva y negativa) del boom minero en el desarrollo del sur peninsular -ya abordado por autores como A. Escudero (1997), p. ej.-, puede afirmarse que el grueso de sus poblados mineros experimentó cierto florecimiento en dicho periodo (último tercio del siglo XIX primero del $X X$ ), tanto económico como cultural. Los mineros, castigados, si se quiere ver así, por la dureza de un trabajo potencialmente mortal y por las arduas condiciones de vida en un entorno contaminado y degradado, tuvieron acceso, como contrapartida, a mejores infraestructuras sanitarias, coberturas sociales y espacios lúdicos. También, en muchas ocasiones, a una educación de calidad para los estándares de la época, lo que fortaleció sus aptitudes para el aprendizaje y el pensamiento libre; es por ello que las minas fueron un buen caldo de cultivo para el movimiento obrero.

En suma, y con base en todo lo expuesto, se puede concluir que el contexto cultural inherente a los habitantes de estos enclaves (independientemente de su localización geográfica) fue moldeado por la actividad minera. En ella construyeron sus modos de pensar, ser y sentir, una manera de vivir que tuvo en el concepto clásico de Carpe diem una máxima y que se convirtió en un elemento diferenciador frente al resto de trabajadores de los territorios circundantes, especialmente los vecinos agricultores. El paisaje de la mina se configuró así como una unidad bien definida y delimitada en su territorio, tanto geográficamente como en la esfera social. Todo lo cual dio lugar a un complejo sistema identitario rastreable a nivel internacional y formado a partir de la conjunción de binomios opuestos: capital-obrero, colono-nativo, precariedad-progreso, religión-vicio, vida-muerte; o, si se permite la licencia, a la gestación de una raza minera orgullosa de sí misma.

\section{AGRADECIMIENTOS}

Este trabajo recoge parte de los resultados alcanzados en el marco del proyecto Minas de Sierra Morena: los colores de la Tierra, financiado por la Dirección General de Bellas Artes y Bienes Culturales y de Archivos y Biblio- tecas del Ministerio de Educación, Cultura y Deporte de España (Convocatoria 18.11.337C.473), y desarrollado desde Eiffel Lab bajo la dirección de Marta Santofimia Albiñana, a quien agradecemos tanto la invitación para participar en su equipo como sus impagables consejos, sugerencias y orientaciones.

\section{BIBLIOGRAFÍA}

$\mathrm{ABC}$

1933 "Tharis. Un prodigio de organización en la minería moderna", Blanco y negro, 29 de enero de 1933, pp. 105-109.

ALVES

1997 Minas de S. Domingos. Génese, formação social e identidade mineira, Campo Arqueológico de Mértola, Mértola.

\section{ANIEVAS}

1910 "Visita á las minas de El Rincón", Diario de Córdoba de comercio, industria, administración, noticias y avisos, 22 de agosto de 1910, p. 2

ARENAS POSADAS, C.

2007 "Trabajo y relaciones laborales en el despegue de la minería mundial (1890-1940)", en PÉREZ DE PERCEVAL VERDE, M. A.; LÓPEZ-MORELL, M. A.; SÁNCHEZ RODRÍGUEZ, A. (Eds.): Minería y desarrollo económico en España, Instituto Geológico y Minero de España, Madrid, pp. 219-235.

\section{AUTE NAVARRETE, F. J.}

2004 "La mina como génesis", en AA.VV. (2004): PeñarroyaPueblonuevo. A cielo abierto, Cajasur Publicaciones, Córdoba, pp. 231-294.

\section{AVERY, D.}

1985 Nunca en el cumpleaños de la Reina Victoria. Historia de las minas de Río Tinto, Labor, Barcelona.

\section{BENSON, J.}

1980 British Coal-Miners in the Nineteenth Century: A Social History, Holmes \& Meiers, Nueva York.

BURKE-GAFFNEY, B.

2002 "Hashima, the Ghost Island", Cabbinet 7, publicación electrónica.

\section{CALVO REBOLLAR, M}

2013 "He dejado mi alma en prenda en la tienda de la empresa. La utilización de fichas y vales en el pago de salarios en las minas de carbón de Estados Unidos", De Re Metallica 20, pp. 13-34

\section{CANO SANCHIZ, J.M.}

2012a La minería y la metalurgia del cobre como elementos de industrialización: análisis arqueológico del complejo británico de Cerro Muriano (Córdoba), Tesis Doctoral (identificador: http://hdl.handle.net/10396/7947), Servicio de Publicaciones de la Universidad de Córdoba, Córdoba. 
2012b "Babel en la mina. El campamento minero como modelo de asentamiento en el mundo industrializado: Cerro Muriano (Córdoba)", Munibe Antropologia - Arkeologia 63, pp. 321-343.

2013 Reseña del documental La Madre: una historia de colonialismo industrial, De Re Metallica 20, p. 100.

\section{CARLONI FRANCA, A.}

2006 "La mujer minera, perspectivas antropológicas y vivenciales", en RÁBANO, I.; MATA-PERRELLÓ, J. M. (Eds.) Patrimonio geológico y minero: su caracterización y puesta en valor, Cuadernos del Museo Geominero 6, Instituto Geológico y Minero de España, Madrid, pp. 143-147.

\section{CASTILLO MARTOS, $\mathrm{M}$}

2005 "Fabricación de ácido sulfúrico en Riotinto. Una industrialización en las minas", en PUCHE RIART, O.: AYARZAGÜENA SANZ, M. (Eds.): Minería y Metalurgia históricas en el Sudoeste Europeo, Sociedad Española para la Defensa del Patrimonio Geológico y Minero, Madrid, pp. 383-393.

CAVANILLAS, J.

1915 Memoria sobre las minas de Cerro Muriano, Escuela Especial de Minas de Madrid, Hemeroteca de la E.T.S.I. de Minas de la Universidad Politécnica de Madrid.

\section{CHASTAGNARET, G.}

2000 L'Espagne, puissance minière dans l'Europe du XIXe siècle, Casa de Velázquez, Madrid.

2007 "La minería española del XIX: de terreno a objeto de investigación", en PÉREZ DE PERCEVAL VERDE, M. A. LÓPEZ-MORELL, M. A.: SÁNCHEZ RODRÍGUEZ, A (Eds.): Minería y desarrollo económico en España, Instituto Geológico y Minero de España, Madrid, pp. 35-45.

\section{COHEN AMSELEM, A. et alii}

2006 "La siniestralidad laboral en la minería y la industria de Peñarroya durante la primera mitad del siglo XX", Ería: Revista cuatrimestral de geografía 69, pp. 75-95

\section{COLECTIVO PROYECTO ARRAYANES}

2007 "El valor universal del patrimonio minero-industrial", $P H$ Boletín 61, pp. 64-103.

2011 Linares 1875. H. J. Rose, un clérigo inglés en el distrito minero, Colectivo Proyecto Arrayanes, Linares.

\section{DELGADO DOMÍNGUEZ, A. (Coord.)}

2006 Catálogo del Museo Minero de Riotinto, Fundación Río Tinto, Riotinto.

\section{DELGADO DOMÍNGUEZ, A. et alii}

2013 "La catalogación del patrimonio minero industrial de la Cuenca Minera de Riotinto mediante la aplicación del Sistema de Información Geográfico (SIG)", De Re Metallica 20, pp. 83-95.

\section{DOMIINGUEZ DOMÍNGUEZ, C}

2013 In Loving Memory. Una mirada a nuestro pasado minero. Los cementerios británicos de Huelva, Ediciones Consulcom, Huelva.
ELLIS, F.

1983 Las transnacionales del banano en Centroamérica, Editorial Universitaria Centroamericana, San José

ENADIMSA (EMPRESA NACIONAL ADARO DE INVESTIGACIONES MINERAS, S. A.)

1986 Libro Blanco de la Minería Andaluza, 2 tomos, Consejería de Economía y Fomento, Dirección General de Industria, Energía y Minas, Sevilla.

\section{ENGELS, F.}

1976 The Condition of the Working Class in England, Panther Books, Londres (1 $1^{\mathrm{a}}$ Ed. del original en alemán: 1845).

\section{ESCUDERO, A}

1996 "Pesimistas y optimistas ante el «boom» minero", Revista de Historia Industrial 10, pp. 69-91.

\section{ESTADISTICA MINERA}

1916 Estadística Minera de España, año 1916, Madrid.

\section{FERNÁNDEZ CALVO, A.}

1987 "La minería y el movimiento obrero en Puertollano durante la Guerra Europea", Cuadernos de Estudios Manchegos 17 , pp. $187-214$

\section{FERNÁNDEZ FERNÁNDEZ, E.; GARCÍA ARANA, A.}

2012 "Itinerarios turístico-culturales por Sierra Morena: propuestas para la valorización y gestión del patrimonio territorial", en Actas de las I Jornadas Andaluzas de Patrimonio Industrial y de la Obra Pública (Sevilla, 25-27 de noviembre de 2010), Fundación Patrimonio Industrial de Andalucía, Sevilla, documento electrónico

\section{FLETA GONZÁLEZ, A. et alii}

2005 "Desarrollo minero e industrial, migraciones y poblamiento en el entorno de Peñarroya (Córdoba) durante el primer tercio del siglo XX", Revista de Demografía Histórica XXIII1, pp. $107-138$

FOSTER, J.

1988 "Beyond the boundaries: life in the Copper Mines of Lake Superior", Michigan Collection of Pioneer History 11, pp. 175-186.

\section{GARCÍA VALENZUELA, M}

2005 Sewell, patrimonio de la minería chilena, Memoria de Licenciatura, Santiago de Chile (publicación electrónica)

GONZÁLEZ JÓDAR, A.; SANCHIS, J.M.

2012 "Desagües y socavones de Sierra Almagrera, Cuevas del Almanzora, Almería", Hastial 2, pp. 1-60.

\section{GONZÁLEZ VERGARA, O.}

2012 "Fuentes documentales alternativas para el estudio de la Arqueología Industrial. Los cantes mineros de la Sierra Minera de Cartagena-La Unión (Murcia, España)", Llámpara, patrimonio industrial 5, p. 58-67. 
2013 "Ser niño en un entorno industrial contemporáneo. Ejemplos desde la Sierra Minera de Cartagena - La Unión (Murcia)", El Futuro del Pasado 4, pp. 157-173.

HARVEY, Ch.; TAYLOR, P.

1987 "Mineral Wealth and Economic Development: Foreign Direct Investment in Spain, 1851-1913", The Economic History Review 40-2 (new series), pp. 185-207.

\section{HERNANDO LUNA, R.}

1989 Aportación al estudio de la minería cordobesa: explotaciones de plomo, plata, cinc y cobre (1850-1929). Tesis Doctoral (inédita), Universidad de Córdoba.

\section{HERNANDO LUNA, R.; HERNANDO FERNÁNDEZ, J. L.}

1999 "Estudios socioeconómicos: la aportación trágica de los trabajadores al desarrollo de la minería en la provincia de Córdoba. Grandes catástrofes mineras (1854-1918)", Boletín de la Real Academia de Córdoba 136, pp. 71-87.

HUDSON, K.

1976 A Pocket Book for Industrial Archaeologist, John Baker, Londres.

\section{INSTITUTO DE REFORMAS SOCIALES}

1910 Información sobre el trabajo en las minas, á propósito de las peticiones que las Sociedades obreras elevaron al Gobierno el año 1909, Madrid.

KEARNS, R.H.B.

1982 The Mines of Broken Hill, Broken Hill, A Pictorial History, Broken Hill Historical Society, Broken Hill.

\section{LÓPEZ MOHEDANO, J.}

2004 "Peñarroya-Pueblonuevo: recuerdos e historia", en AA.VV.: Peñarroya-Pueblonuevo. A cielo abierto, Cajasur Publicaciones, Córdoba, pp. 37-230.

2011 "Las construcciones de estilo francés en Peñarroya-Pueblonuevo", Arte, Arqueología e Historia 18, pp. 107-120.

MARTÍNEZ CALATRAVA, V.

2001 Historia y estadística del fútbol español, vol. I, Fundación Zerumuga, Barcelona.

\section{MARTÍNEZ CARRIÓN, J.M.}

2005 "Estatura, salud y nivel de vida en la minería del sureste español, 1830-1936", en VIII Congreso de la Asociación Española de Historia Económica (Galicia, septiembre de 2005), documento electrónico.

2007 "Niveles de vida en la minería española", en PÉREZ DE PERCEVAL VERDE, M. A.; LÓPEZ-MORELL, M. A.: SÁNCHEZ RODRÍGUEZ, A. (Eds.): Minería y desarrollo económico en España, Instituto Geológico y Minero de España, Madrid, pp. 237-255.

\section{MARTíNEZ GONZÁLEZ, C.; MENÉNDEZ NAVARRO, A.}

2006 "El Instituto Nacional de Silicosis y las enfermedades respiratorias profesionales en España", en ÁLVAREZ SALA WALTHER, J.L.; CASAN CLARÀ, P.; VILLENA GARRIDO, V. (Eds.): Historia de la neumología y la cirugía torácica españolas, Sociedad Española de Neumología Madrid, pp.145-162.
MAWSON, P.

1958 A vision of steel: the life of G. D. Delprat, C.B.E., General Manager of B.H.P. 1898-1921, F.W. Cheshire, Melbourne.

MAYERS, L.

2009 Voices from the Dressing Floors of the Cornish mines and quarries (1773-1950), Blaize Baley Books, Inglaterra.

\section{MENÉNDEZ-NAVARRO, A}

2012 "Trabajo, enfermedad y asistencia en las minas de Almadén (Ciudad Real), siglos XVI-XX", De Re Metallica 19, pp. 95-102.

NAVARRO GARCÍA, J.L.; IINO, A.

1989 Cantes de las minas, Ediciones de La Posada, Córdoba.

NUÑEZ DE ARENA, M.; TUÑÓN DE LARA, M.

1979 Historia del movimiento obrero español, Nova Terra, Barcelona.

OLIVIER, W.; OLIVIER, S.

2005 Touring in South Africa, Struik Publishers, Ciudad del Cabo.

ORCHE, E.

2006 "Los milagros de la Virgen de la Candelaria de Copacabana en la minería colonial del alto Perú durante los siglos XVI y XVII", De Re Metallica 6-7, pp. 83-90.

ORTEGA ANGUIANO, J. A.

2003 "El Tren de la Sierra. Geografía humana y Arqueología Industrial en el Ferrocarril de Córdoba a Belmez", Paso a nivel 1, pp. 63-75.

PALMER, M; NEAVERSON, P.

1987 The Basset Mines. Their history \& industrial archaeology, Northern Mine Research Society, Sheffield.

1994 Industry in the landscape: 1700-1900, Routledge, Londres y Nueva York.

PENCO VALENZUELA, F.

2010 Cerro Muriano, Sitio Histórico. Historia de la minería en Córdoba, Almuzara, Córdoba.

\section{PRADOS ROSALES, L.}

2011 Patrimonio Industrial en el Valle del Alto Guadiato (Córdoba): arquitecturas, infraestructuras y paisajes, Tesis Doctoral (inédita), Universidad de Sevilla.

PEINADO RODRÍGUEZ, M.; ANTA FÉLEZ, J.L.

2010 "Campesino versus minero: encuentros y desencuentros en una agrociudad (1850-1930)", Revista de Antropología Experimental 10, pp. 407-422.

PÉREZ DE PERCEVAL VERDE, M. A.; LÓPEZ-MORELL, M. A.

2007 "Introducción. Una visión general del sector minero en la Historia Contemporánea española", en PÉREZ DE PERCEVAL VERDE, M. A.; LÓPEZ-MORELL, M. A.; SÁNCHEZ RODRÍGUEZ, A. (Eds.): Minería y desarrollo económico en España, Instituto Geológico y Minero de España, Madrid, pp. 17-32. 
PUCHE RIART, O.

2001 "La minería no energética", en AYALA-CARCEDO, F. J. (Dir.): Historia de la tecnología en España, vol. 1, Valatenea, Barcelona, pp.119-232.

RAMOS, J.

1914 "Cerro-Muriano. Función recreativa", El País, 9 de agosto de 1914 , p. 5.

REGALADO ORTEGA, Mª de la C.; MORENO BOLAÑOS, A.; DELGADO DOMÍNGUEZ, A.

2010 "Club Inglés de Bella Vista. Minas de Riotinto (Huelva)", De Re Metallica 15, pp. 43-56.

ROMERO MACÍAS, E.; PÉREZ MACÍAS, J. A.; PÉREZ LÓPEZ, J. M.

2005 "Declaración de Bien de Interés Cultural en la categoría de Sitio Histórico de la cuenca minera de Tharsis y La Zarza en Huelva", en PUCHE RIART, O; AYARZAGÜENA SANZ, M. (Eds.): Minería y Metalurgia históricas en el Sudoeste Europeo, Sociedad Española para la Defensa del Patrimonio Geológico y Minero, Madrid, pp. 651-657.

\section{SÁNCHEZ PICÓN, A.}

1997 "Minerías en Andalucía: una perspectiva desde la historia económica", en NAVARRO FLORES, A.; GARCÍAROSSELL MARTIINEZ, L. (Coords): Recursos naturales y medio ambiente en el sureste peninsular, Instituto de Estudios Almerienses, Almería, pp. 535-554.

2005 "Un imposible capitalismo: empresas, tradiciones organizativas y marco institucional en la minería del plomo española del siglo XIX", Revista de Historia Industrial 29 pp. 13-54

\section{SÁNCHEZ SÁNCHEZ, I.}

2001 "Propaganda de ideas en la España del siglo XIX", en ORTIZ HERAS, M.; RUIZ GONZÁLEZ, D.; SÁNCHEZ SÁNCHEZ, I. (Coords.): Movimientos sociales y Estado en la España contemporánea, Ediciones de la Universidad de Castilla - La Mancha, pp. 153-202.

\section{SANTIAGO CUMBRERAS, A.}

2004 "Posibilidades turísticas de poblados y explotaciones mineras" en PÉREZ MACÍAS, J. A.; ROMERO MACÍAS E. (Coords.): Metallum. La minería suribérica, Servicio de Publicaciones de la Universidad de Huelva, Huelva, pp. 281-298.

\section{SHORTRIDGE, B.G.; SHORTRIDGE, J.R}

1998 The taste of American place. A Reader on Regional and Ethnic Foods, Rowman \& Littlefield, Lanham.

SIERRA ÁLVAREZ, J.

1987 "Minería y gestión de la mano de obra en la Andalucía decimonónica. El caso de Villanueva de las Minas (SeviIla)", Anales de Geografía de la Universidad Complutense 7, pp. 667-674.

1990 El obrero soñado: ensayo sobre el paternalismo industrial (Asturias, 1860-1917), Siglo XXI de España Editores, Madrid

SOLER JÓDAR; J.A.; HANSEN, L.K.

2013 "Ingenieros noruegos en las minas de Almería del siglo XIX", De Re Metallica 20, 65-81.
SLOTTA, R. (Ed.)

200575 Jahre Deutsches Bergbau-Museum Bochum (1930 bis 2005); vom Wachsen und Werden eines Museums, Deutsches Bergbau-Museum, Bochum.

TONE, A.

1997 The Business of Benevolence: Industrial Paternalism in Progressive America, Cornell University Press, Ithaca.

\section{TORRES HERNÁNDEZ, L.}

2011 "La taranta en Linares (Jaén): un cante minero entroncado en la cultura popular", De Re Metallica 16, pp. 75-80.

\section{TORTELLA CASARES, T}

2000 A Guide to Sources of Information on Foreing Investment in Spain (1780-1914), Section of Business and Labour Archives of the International Council on archives by the International Insitute of Social History, Ámsterdam.

\section{VAQUERIZO GIL, D. (Coord.)}

1994 Minería y metalurgia en la España prerromana y romana, Diputación Provincial de Córdoba, Córdoba.

\section{VENTURA VILLANUEVA, A.}

1993 "Susum ad montes S(ocietatis) S(isaponensis): nueva inscripción tardorrepublicana de Corduba", Anales de Arqueología Cordobesa 4, pp. 49-61.

\section{VERA CASTILLEJO, V.}

2004 "El factor humano", en AA.VV.: Peñarroya-Pueblonuevo. A cielo abierto, Cajasur Publicaciones, Córdoba, pp. 377-396.

VERNON, M.; VERNON, R. W.

2007 "Reginald Bonham Carter (1872-1906)", La Galena 2 (revista electrónica del Colectivo Proyecto Arrayanes).

WILLIES, L.

2009 Lead and leadmining, Shire Library, Oxford. 